\title{
Third harmonic injection by MMC-swiss rectifier for offshore HVDC wind turbine applications
}

\author{
Ali Salam Al-Khayyat ${ }^{1}$, Mustafa Jameel Hameed ${ }^{1}$, Alyaa Muhsen Manati ${ }^{1}$ \\ ${ }^{1,2,3}$ Department of Electrical and Electronics Engineering, University of Thi-Qar, Al-Nassiryah, Thi-Qar, Iraq
}

\section{Article Info}

Received Jan 14, 2019

\section{Keyword:}

Modular Multilevel

Converter, Swiss rectifier

Third harmonic injection

Voltage Source Converter

HVDC.

\begin{abstract}
In this paper, Modular Multilevel Converter MMC-Swiss rectifier for harmonic mitigation is presented and simulated by PLECS software package. The mathematical calculations and system simulation are performed for a converter with nominal power of $400 \mathrm{MW}$ and 400KV DC. The characteristic of Swiss rectifier including the operation principle, modulation strategy and relevant equations are described in detail. The MMC is used as a combination with Swiss rectifier because of its simplicity to be integrated for applications that required different level of voltages and currents, such as offshore wind turbine. Where, there is a trend to generate the electricity and transmit it in DC form due to its economic reasons. Therefore, the usage of MMC-Swiss rectifier is viable for High Voltage Direct Current HVDC applications. The contribution of Swiss rectifier is to make the current drawn from the supply by a converter, pure sinusoidal and this achieved by injecting third harmonic current in the circulating current from the DC side. Thus, this would reduce the THD and improve the power quality of the AC side currents.
\end{abstract}

\section{Corresponding Author:}

\author{
Ali Salam Al-Khayyat ${ }^{1}$ \\ Departement of Electrical and Electronics Engineering, \\ College of Engineeing, \\ University of Thi-Qar, Al-Nassiryah, Thi-Qar, Iraq \\ E-mail: ali-al-khayyat@utq.edu.iq
}

\section{Introduction}

The development of Power Electronic industry has increased the usage of non-linear loads. The harmonic in line current is an issue and this is caused by non-linear loads, which are considered as source of harmonic current. Finding the solution for reducing harmonic distortion is an issue in research and engineering field.

For three-phase Power Factor Correction (PFC) system, different topologies have been proposed for mitigating harmonics and some are based on third-harmonic current injection technique. Applications such as HVDC, electric vehicle battery charger, DC drive and future electric aircraft inherently require a converter from AC to DC [1,2]. One of the converter topologies, which are based on third-harmonic current injection, is Swiss rectifier. This rectifier would reduce the harmonics of input line current and under operating condition; it provides high efficiency [3]. In addition, it is not only used for harmonic improvement, but also it is fully controllable.

Swiss rectifier is introduced for first time in [4] and [5]. The structure of Swiss rectifier consists of three-phase diode rectifier with active switches placed in the main path of the current to/from the load, which works as third-harmonic current injection circuit.

HVDC offshore wind turbine has drawn the attention recently. Thus, this converter is appropriate for this purpose. The Modular Multilevel Converter MMC based on Voltage Source Converter VSC is suitable for HVDC applications. The MMC-VSC would improve the safety of electric power supply, where VSC would 
provide decouple control for active and reactive power and back up the AC grid voltage. The MMC would be used in a combination with the Swiss rectifier. Where, a controlled DC voltage source as MMC branch will be connected to Swiss rectifier.

In this paper, the MMC-Swiss rectifier for offshore HVDC wind turbine applications would be implemented and controlled. The operation principle of this converter, their modulation and the relevant equations to get the rectifier parameters would be explained in details. PLECS ${ }^{\circledR}$ simulation package has been used in this paper due to its powerful tool in power electronic components and their control.

The outline of this paper would be as follows, after an introduction, Swiss rectifier and the related equations of voltage and current would be presented. Then, the modulation of Swiss rectifier switches is explained. After that, the modulation and Simulink result would be introduced. Then, mathematical calculations for voltage and current are explained. The results from the simulation and calculation are compared and discussed.

In order to understand the Swiss rectifier, the basic knowledge of three-phase diode rectifier is required. The source of diode rectifier is assumed ideal and AC side inductance is small to the extent that can be neglected. The PLECS software is used to obtain the result, which is based on simple calculation for the three-phase diode rectifier equations, which is shown in Figure 1.

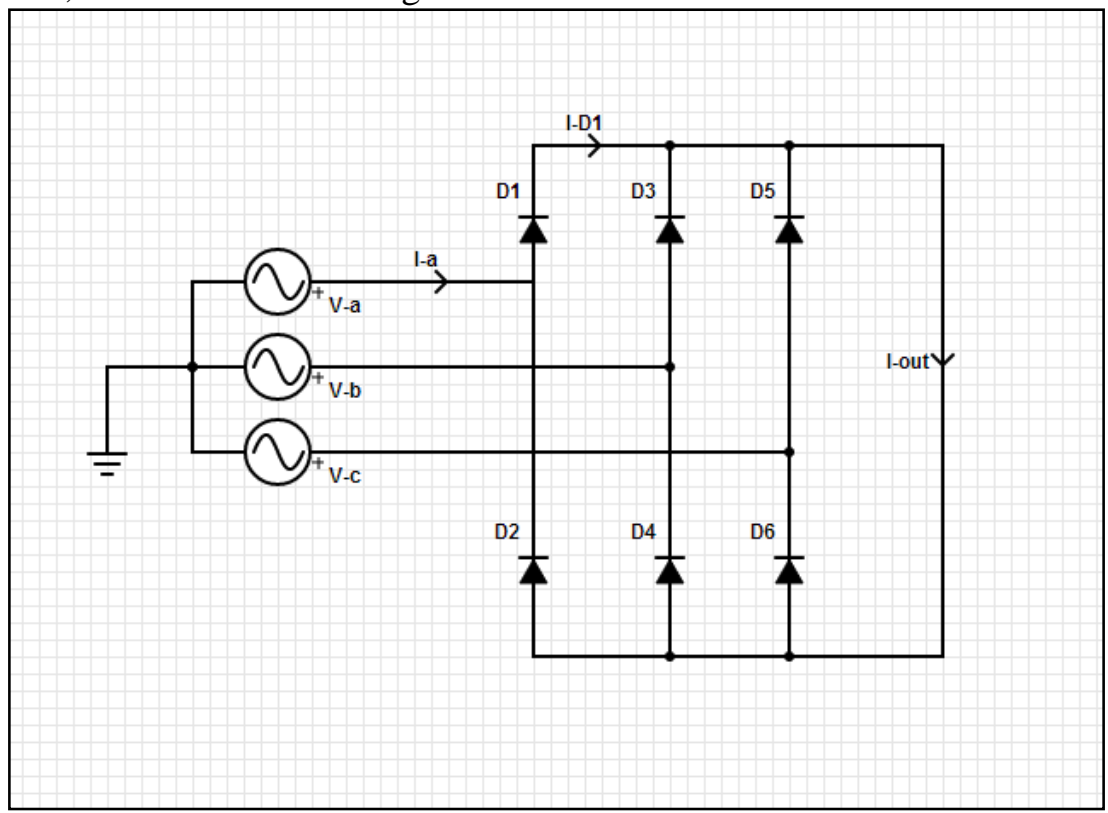

Figure 1: Three-phase Diode Bridge

The ideal three-phase source are represented by:

$$
\left\{\begin{array}{l}
V_{a}=V_{m} \operatorname{Cos}(w t) \\
V_{b}=V_{m} \operatorname{Cos}(w t-2 \pi / 3) \\
V_{c}=V_{m} \operatorname{Cos}(w t-4 \pi / 3)
\end{array}\right.
$$

The output current $\left(I_{\text {out }}\right)$ is assumed to be positive and this means that the load is sensitive to the rectifier output. The diode behaviour of the three-phase diode rectifier is shown in Table 1, which represents the rectifier diode state functions $[1,6,7]$.

Table 1: Diode state functions

\begin{tabular}{|l|l|l|l|l|l|l|}
\hline Segment & D1 & D2 & D3 & D4 & D5 & D6 \\
\hline $0<w t<60^{\circ}$ & $\mathbf{1}$ & 0 & 0 & 0 & 0 & $\mathbf{1}$ \\
\hline $60^{\circ}<w t<120^{\circ}$ & 0 & 0 & $\mathbf{1}$ & 0 & 0 & $\mathbf{1}$ \\
\hline $120^{\circ}<w t<180^{\circ}$ & 0 & $\mathbf{1}$ & $\mathbf{1}$ & 0 & 0 & 0 \\
\hline $180^{\circ}<w t<240^{\circ}$ & 0 & $\mathbf{1}$ & 0 & 0 & $\mathbf{1}$ & 0 \\
\hline $240^{\circ}<w t<300^{\circ}$ & 0 & 0 & 0 & $\mathbf{1}$ & $\mathbf{1}$ & 0 \\
\hline $300^{\circ}<w t<360^{\circ}$ & $\mathbf{1}$ & 0 & 0 & $\mathbf{1}$ & 0 & 0 \\
\hline
\end{tabular}


The rectifier can produce positive and negative output voltage, which is equal to the maximum and minimum phase voltage respectively, as expressed in Equations (2) and (3):

$$
\begin{aligned}
& V_{A}=\max \left(v_{a}, v_{b}, v_{c}\right) \\
& V_{B}=\min \left(v_{a}, v_{b}, v_{c}\right)
\end{aligned}
$$

The Fourier series of the positive and negative output voltages and the mean output voltage of the three-phase rectifier are given by the following Equations:

$$
\begin{aligned}
& V_{A}=\frac{3 \sqrt{3}}{\pi} V_{m}\left[\frac{1}{2}+\sum_{n=1}^{\infty} \frac{(-1)^{n+1}}{9 n^{2}-1} \cos (3 n w t)\right] \\
& V_{B}=\frac{3 \sqrt{3}}{\pi} V_{m}\left[-\frac{1}{2}+\sum_{n=1}^{\infty} \frac{1}{9 n^{2}-1} \cos (3 n w t)\right] \\
& V_{\text {Out }}=V_{A}-V_{B}=\frac{3 \sqrt{3}}{\pi} V_{m}=1.66 V_{m}
\end{aligned}
$$

The spectral components at odd triples are cancelled from the output voltage, because $V_{A}$ and $V_{B}$ have the same spectral. Therefore, the output voltage would be composed from only the $6^{\text {th }}$ multiples of the fundamental frequency. The instantaneous output voltage can be expressed by:

$$
V_{o}(t)=0.9549 V_{m}\left(1-\sum_{n=6 k}^{\infty} \frac{2}{\left(n^{2}-1\right)} \cos \frac{n \pi}{6} \cos n w t\right)
$$

The current shape of the three-phase diode rectifier is not sinusoidal due to harmonics; this is shown in Figure 2. It is required to obtain sinusoidal current for power electronic applications and this would be achieved by employing Swiss rectifier.

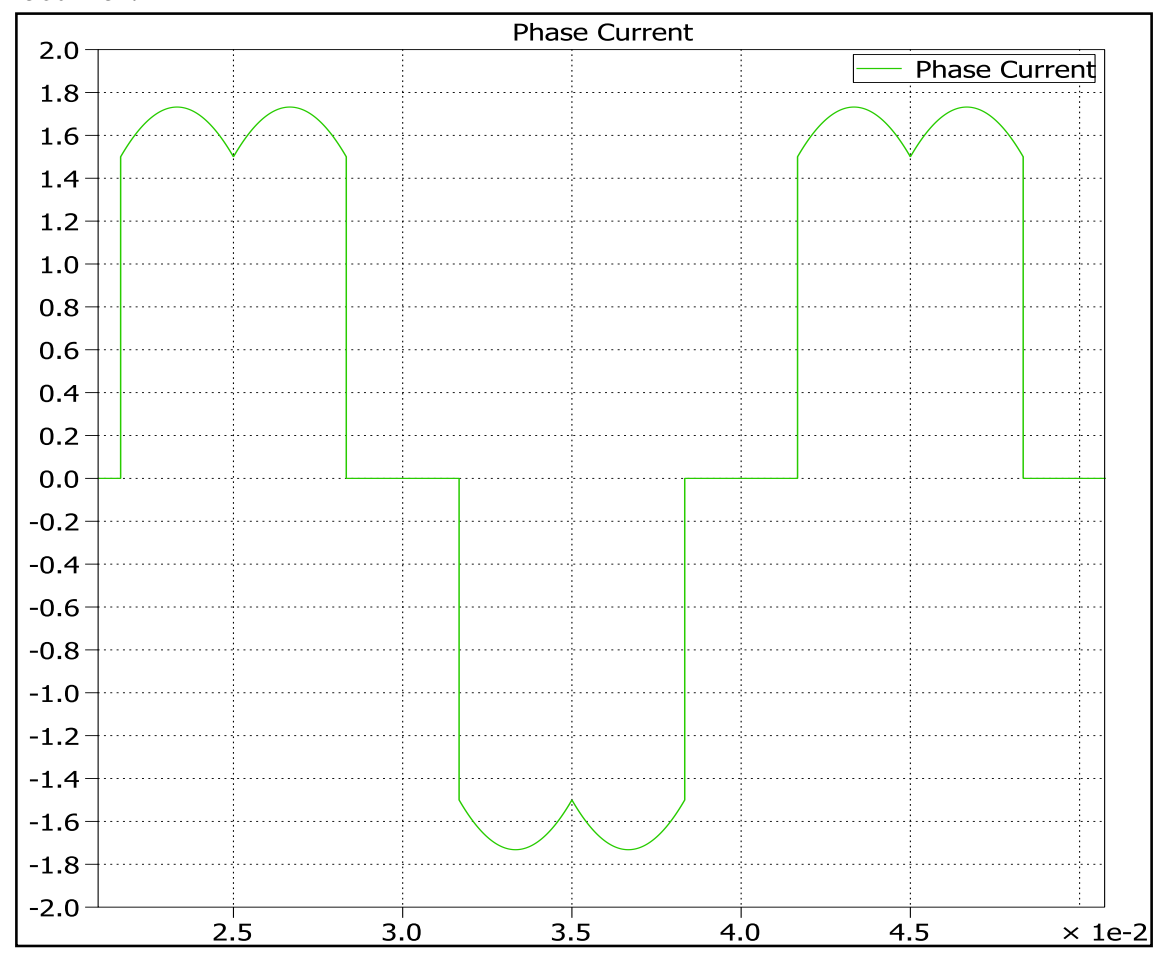

Figure 2: Phase current waveform in three-phase diode rectifier (Time vs. ampere)

The usage of MMC-Voltage Source Converter VSC in the HVDC transmission would add some advantage points, such as the possibility of obtaining independent control for the active and reactive power, and the AC voltage grid can be supported [8-16]. The MMC can be structured from identical sub-modules or cells, which are series connected. That combination would lead to high efficiency, easy scale up, lower device stress, easy manufacturability and reduction in harmonics. Half-bridge or full-bridge cell in each leg can be used in the 
MMC, however, a cell with two-level half-bridge that contain two IGBTs connected in series across a capacitor is popular form in the converter, as shown in Figure 3.

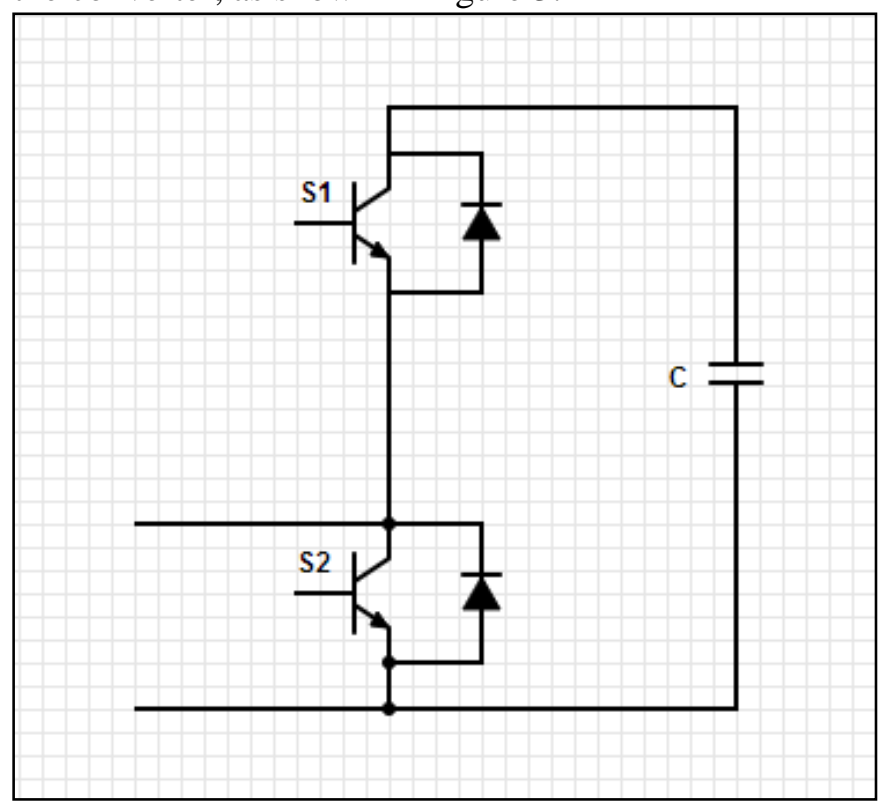

Figure 3. Half-bridge sub-module (SM)

\section{MMC voltage and current description}

The MMC can be controlled via the switching strategy. It would be assumed that the number of active submodule for each phase is equal to $\mathrm{n}$. Thus, the number of active sub-module in upper MMC leg is given by the following relationship:

$$
m_{\text {up }, i}=n-m_{\text {low }, i}
$$

Where $\left(m_{u p, i}\right)$ and $\left(m_{\text {low }, i}\right)$ are the numbers of active sub-module in the upper and lower part of the leg respectively and $(i=a, b$ and $c)$. The capacitor DC voltage and current flow direction would be an issue to be considered in selecting which sub-modules are active or not [17]. When the average value of the DC bus is $V_{D C}$ and this value is the same for the capacitors of active sub-modules, then the voltage of capacitor submodule is given as:

$$
V_{c a p}=V_{D C} / n
$$

Thus, from the switching state of the active sub-module, where each individual sub-module has two different terminal voltage values, 0 and $V_{\text {cap }}$. So, a series expansions of the terminal output voltage of each individual sub-module would represent the upper and lower voltages, as follows:

$$
\begin{gathered}
V_{u p, i}=\sum_{i=1}^{n}\left(S_{\text {up }, i}\right)\left(V_{\text {cap }, \text { up }, i}\right)+L_{\text {arm }} \frac{d i_{\text {up }, i}}{d t} \\
V_{\text {low }, i}=\sum_{i=1}^{n}\left(S_{\text {low }, i}\right)\left(V_{\text {cap }, \text { low }, i}\right)+L_{\text {arm }} \frac{d i_{\text {low }, i}}{d t}
\end{gathered}
$$

Where the switching states of upper and lower legs are denoted by $S_{u p, i}$ and $S_{l o w, i}$ respectively. If $S_{u p, i}$ or $S_{\text {low }, i}$ is equal to 1 , the sub-module would be active otherwise it is inactive [17]. The converter phase current contains two components, which are the DC and AC current component. The following equations represent the current, which has two currents, upper and lower legs for each phase. The relationship between the upper and lower arm currents, and, the circulating current between the MMC phases $(i=a, b$ and $c)$ is shown in following Equations:

$$
\begin{gathered}
i_{i}=i_{\text {up }, i}+i_{\text {low }, i} \\
i_{u p, i}=\frac{i_{i}}{2}+i_{\text {circ }, i}
\end{gathered}
$$




$$
i_{\text {low }, i}=-\frac{i_{i}}{2}+i_{\text {circ }, i}
$$

Therefore:

$$
\begin{gathered}
i_{\text {up }, i}=i_{\text {up }, a c, i}+i_{\text {circ }, i} \\
i_{\text {low }, i}=i_{\text {low }, a c, i}+i_{\text {circ }, i}
\end{gathered}
$$

Where $i_{c i r c, a}, i_{c i r c, b}$ and $i_{c i r c, c}$ are the currents flowing and they are depending only on the DC current value. The circulating current equation is given by:

$$
i_{c i r c, i}=\frac{i_{d c}}{3}
$$

Hence, the upper and lower arm currents can be expressed as AC and DC components:

$$
\begin{aligned}
& i_{u p, i}=i_{u p, a c, i}+\frac{i_{d c}}{3} \\
& i_{\text {low }, i}=i_{\text {low }, a c, i}+\frac{i_{d c}}{3}
\end{aligned}
$$

\section{Swiss rectifier}

The harmonics are an issue in the power electronics application, but the development of the power electronic converter that would provide sinusoidal current and inject third-harmonic current has increased the usage of non-linear loads. One of the rectifier topology which achieves that is Swiss rectifier as shown in Figure 4. It provides high rectification efficiency, harmonics reduction in the AC side, and it is fully controllable. The general layout of Swiss converter is that it consists three-phase diode rectifier and some active switches in the main path of the input current, which their function is to inject third-harmonics current based on their switching operation [1,7]. The converter provides currents through both positive and negative switches, $i_{T+}$ and $i_{T-}$. These currents are formed in proportion to two phase voltages that would create the diode bridge output voltages. Then, they are fed back to the mains through the configuration of a current injection, where the sinusoidal input current is created by gating three four-quadrant switches [2]. The calculations of the switches turn-on time and current space vector would be used for the analysis of switches conduction states. The phase currents $i_{a}, i_{b}$ and $i_{c}$ and the rectifier input currents $i_{r a}, i_{r b}$ and $i_{r c}$ are assumed to be equal. In addition, the supply voltages are assumed ideal and sinusoidal.

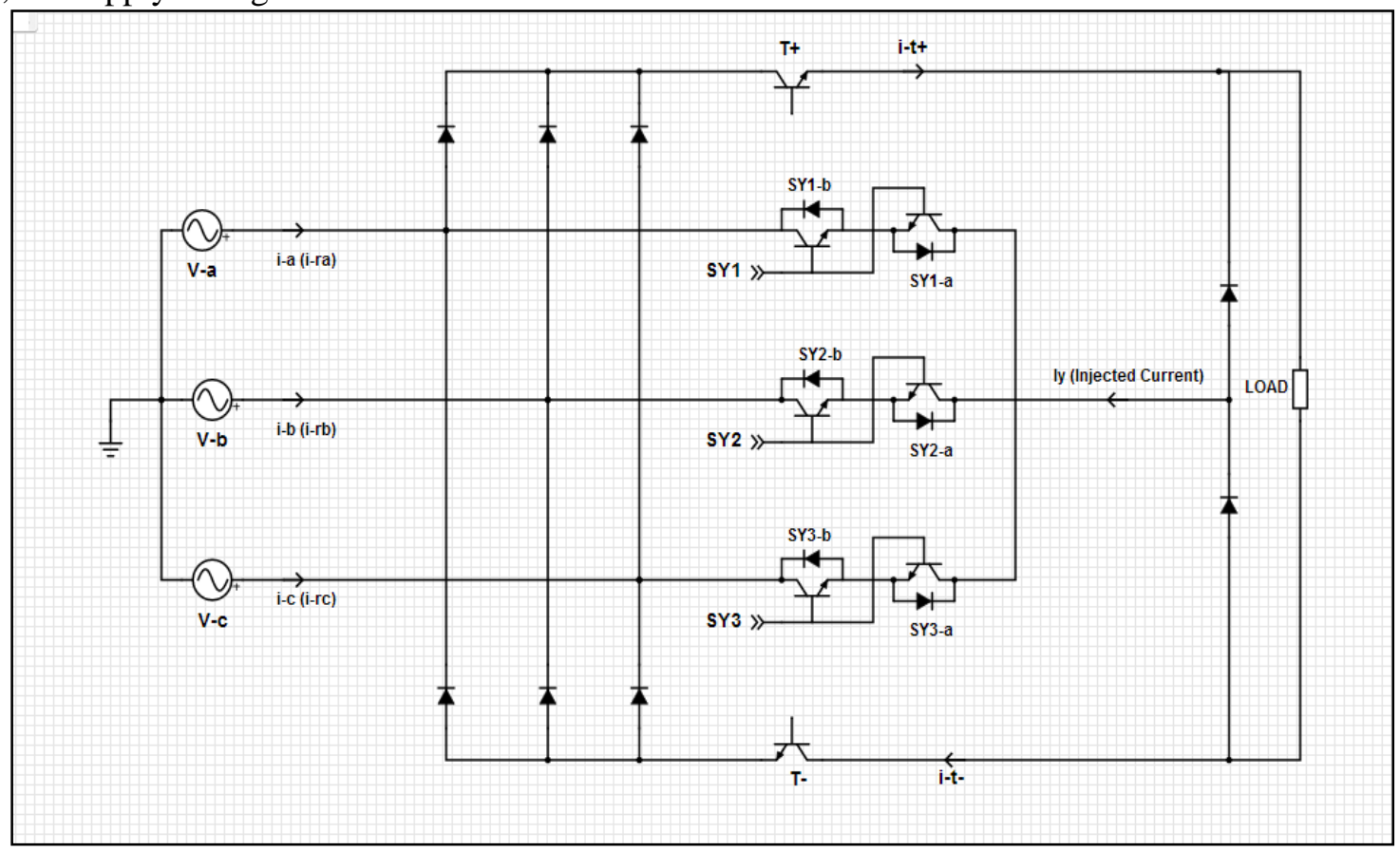

Figure 4. Circuit topology of Swiss Rectifier 


\section{Swiss rectifier modulation}

The Clark transformation is used to transform from the three-phase stationary system into two-phase stationary system known as $\alpha \beta$ stationary frame, as shown in Figure 5.

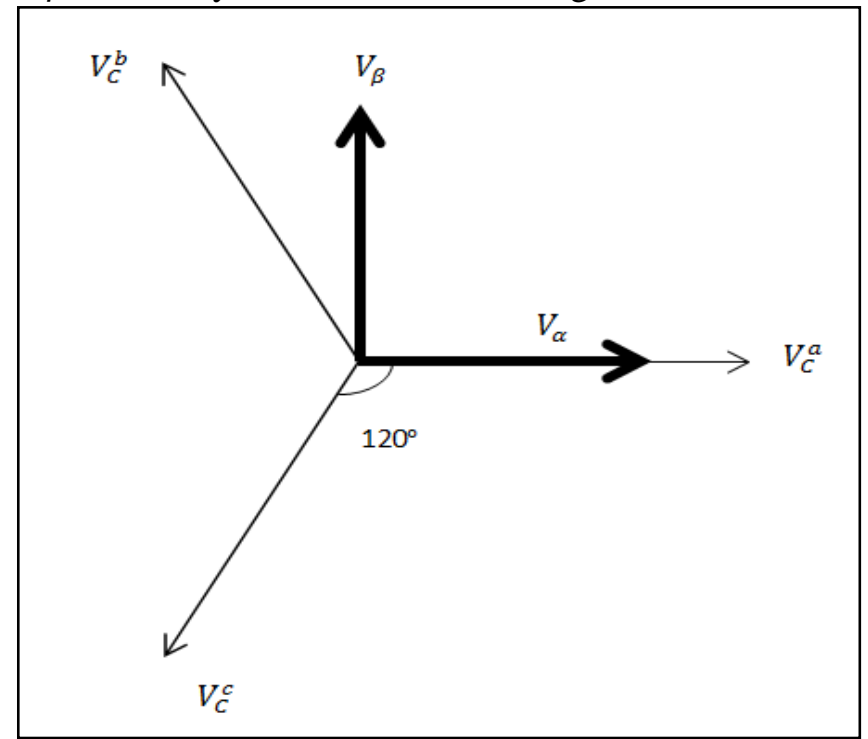

Figure 5. The three-phase and two-phase stationary reference frame of voltage

The mathematical Clark transformation is explained in the following matrix:

$$
\left(\begin{array}{l}
v_{\alpha} \\
v_{\beta}
\end{array}\right)=\frac{2}{3} V_{m}\left(\begin{array}{ccc}
1 & -\frac{1}{2} & -\frac{1}{2} \\
0 & \frac{\sqrt{3}}{2} & -\frac{\sqrt{3}}{2}
\end{array}\right)\left(\begin{array}{c}
V_{(t)}^{a} \\
V_{(t)}^{b} \\
V_{(t)}^{c}
\end{array}\right)
$$

The above equation can be written in another form, which is:

$$
\left(\begin{array}{c}
v_{\alpha} \\
v_{\beta}
\end{array}\right)=V_{m}\left(\begin{array}{c}
\cos (w t) \\
\sin (w t)
\end{array}\right)
$$

Where the phase angle $\varphi$ is defined as:

$$
\varphi=\tan ^{-1}\left(\frac{v_{\beta}}{v_{\alpha}}\right)
$$

This angle is changing between $0^{\circ}$ and $360^{\circ}$, thus it would be divided into six sectors. These six sectors have a length pointing to a vertices of a hexagon and the length of the active space vector is apart from each other's by $60^{\circ}$. Each section of that hexagon is called sector [18]. This is shown in Figure 6.

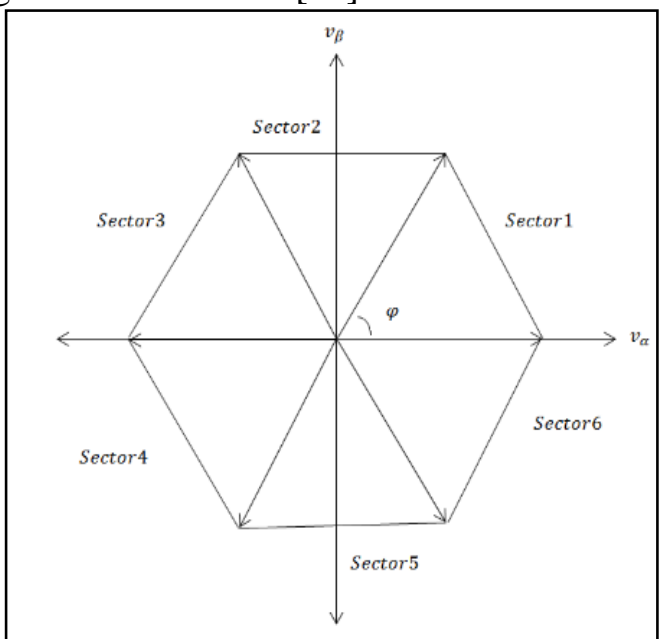

Figure 6. Hexagon of six-space vector of phase angle $\varphi$ [1] 
The modulation is achieved via the switches $S_{y 1}, S_{y 2}$ and $S_{y 3}$ as they are shown in Figure 4, that have six sector intervals $\left[0^{\circ}, 60^{\circ}\right]$. Based on that, the sub-switch $\left(S_{y 1, a b}, S_{y 2, a b}\right.$ and $\left.S_{y 3, a b}\right)$ would be analysed for the interval $\left[0,30^{\circ}\right]$, which means twelve $30^{\circ}$ sectors, e.g., $0<\varphi<30^{\circ}$, would make the main period. Four different state conductions for the main interval $\left[0,30^{\circ}\right]$ would be achieved and they are described by $T_{+}$and $T_{-}$. It should be mentioned that, this would occur in the half-wide sectors of the main periods. Figure 7 shows the four conduction states for $\left[0,30^{\circ}\right]$ of the mains interval, where a combination of the two fast sub-switches would be on and this is described by the switching state of $\mathrm{j}=(\mathrm{ON}, \mathrm{ON})$ and this indicates $\mathrm{j}=\left(T_{+}, T_{-}\right)$. For instance, when $\mathrm{j}=(\mathrm{ON}, \mathrm{ON})$, the rectifier input currents are $i_{r a}=\mathrm{I}_{D C}, i_{r b}=0$ and $i_{r c}=-\mathrm{I}_{D C}[2][4]$. Therefore, the injected current would be expressed as:

$$
i_{T+}-i_{T-}=i_{y}
$$

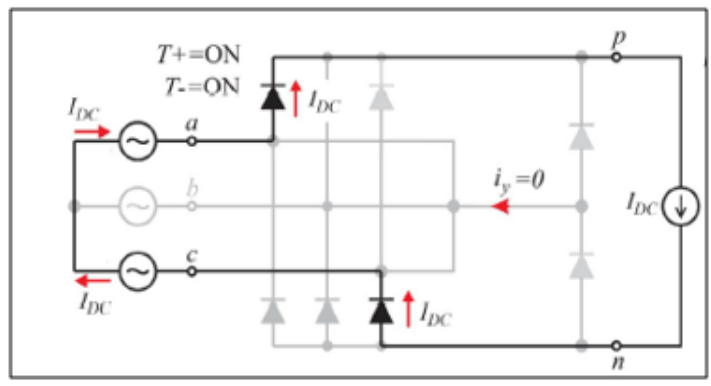

a)

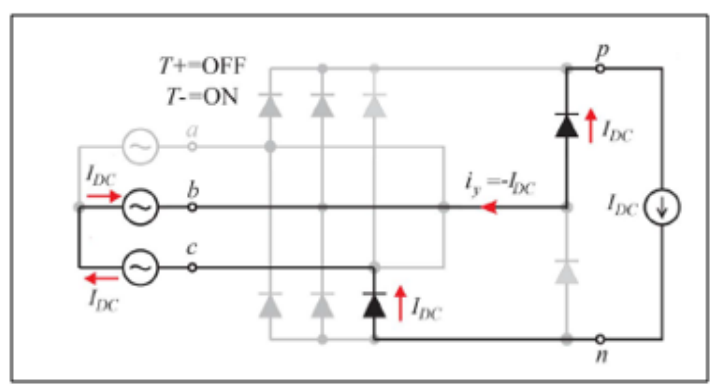

c)

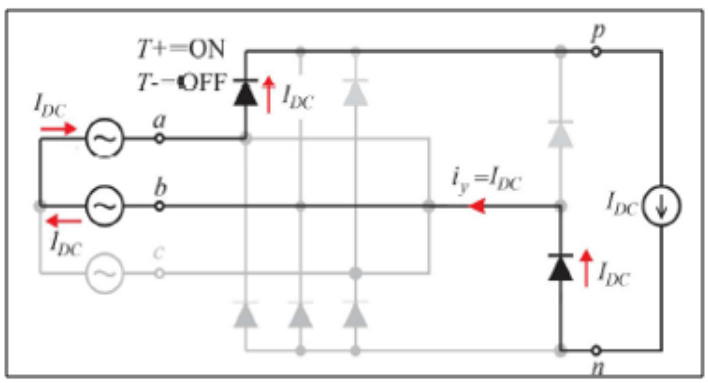

b)

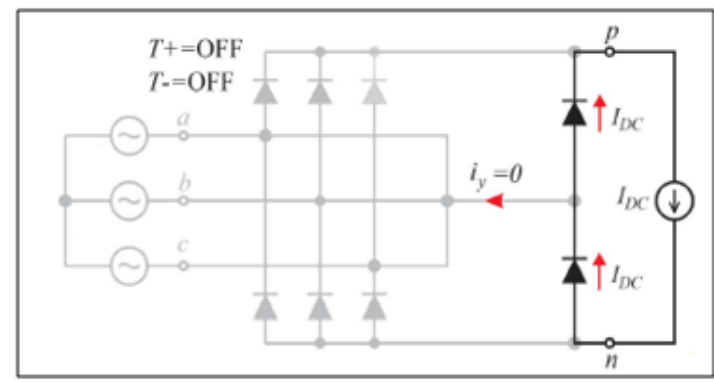

d)

Figure 7. (a)-(d) Conduction States of the Swiss rectifier [2]

The order of first, third and fifth sector intervals $\left[30^{\circ}\right]$ are associated to the switches $S_{y 2}, S_{y 1}$, and $S_{y 3}$ respectively. Then, the input current space vector would be formed if the vector modulation that has the switching sequence of $(\mathrm{ON}, \mathrm{ON})-(\mathrm{ON}, \mathrm{OFF})-(\mathrm{OFF}, \mathrm{OFF})-(\mathrm{ON}-\mathrm{OFF})-(\mathrm{ON}, \mathrm{ON})$. The modulation of the Swiss rectifier injection current related to the switches $S_{y_{1}}, S_{y_{2}}$ and $S_{y_{3}}$ is explain in Table (2).

Table 2: Operation switches of Swiss rectifier

\begin{tabular}{|c|c|c|c|c|c|c|}
\hline Sector & $\boldsymbol{S}_{\boldsymbol{y} 1 \boldsymbol{a}}$ & $\boldsymbol{S}_{\boldsymbol{y} \mathbf{b}}$ & $\boldsymbol{S}_{\boldsymbol{y} \mathbf{a} \boldsymbol{a}}$ & $\boldsymbol{S}_{\boldsymbol{y} \boldsymbol{b} \boldsymbol{b}}$ & $\boldsymbol{S}_{\boldsymbol{y} \mathbf{a} \boldsymbol{a}}$ & $\boldsymbol{S}_{\boldsymbol{y} \boldsymbol{b} \boldsymbol{b}}$ \\
\hline $\mathbf{0}^{\mathbf{0}}-\mathbf{3 0}^{\mathbf{0}}$ & 0 & 0 & 1 & 1 & 0 & 0 \\
\hline $\mathbf{3 0}^{\mathbf{0}}-\mathbf{6 0}^{\mathbf{0}}$ & 0 & 0 & 1 & 1 & 0 & 0 \\
\hline $\mathbf{6 0}^{\mathbf{0}}-\mathbf{9 0}^{\mathbf{0}}$ & 1 & 1 & 0 & 0 & 0 & 0 \\
\hline $\mathbf{9 0}^{\mathbf{0}}-\mathbf{1 2 0}^{\mathbf{0}}$ & 1 & 1 & 0 & 0 & 0 & 0 \\
\hline $\mathbf{1 2 0}^{\mathbf{0}}-\mathbf{1 5 0}^{\mathbf{0}}$ & 0 & 0 & 0 & 0 & 1 & 1 \\
\hline $\mathbf{1 5 0}^{\mathbf{0}}-\mathbf{1 8 0}^{\mathbf{0}}$ & 0 & 0 & 0 & 0 & 1 & 1 \\
\hline
\end{tabular}




\begin{tabular}{|l|l|l|l|l|l|l|}
\hline $\mathbf{1 8 0}^{\mathbf{0}}-\mathbf{2 1 0}^{\mathbf{0}}$ & 0 & 0 & 1 & 1 & 0 & 0 \\
\hline $\mathbf{2 1 0}^{\mathbf{0}}-\mathbf{2 4 0 ^ { \mathbf { 0 } }}$ & 0 & 0 & 1 & 1 & 0 & 0 \\
\hline $\mathbf{2 4 0}^{\mathbf{0}}-\mathbf{2 7 0}^{\mathbf{0}}$ & 1 & 1 & 0 & 0 & 0 & 0 \\
\hline $\mathbf{2 7 0}^{\mathbf{0}}-\mathbf{3 0 0}^{\mathbf{0}}$ & 1 & 1 & 0 & 0 & 0 & 0 \\
\hline $\mathbf{3 0 0}^{\mathbf{0}}-\mathbf{3 3 0}^{\mathbf{0}}$ & 0 & 0 & 0 & 0 & 1 & 1 \\
\hline $\mathbf{3 3 0}^{\mathbf{0}}-\mathbf{3 6 0}^{\mathbf{0}}$ & 0 & 0 & 0 & 0 & 1 & 1 \\
\hline
\end{tabular}

The gate pulses for the third-harmonic injected current by this rectifier can produce with these switching state sequences. Hence, when the third harmonic current injection is controlled, therefore a current with sinusoidal shape in the supply can be obtained $[1,2,28]$.

\section{PLECS modelling results}

The following results are based on PLECS simulation for the system shown in Appendix. The generated thirdharmonic currents is shown Figure 8. The phase current of the diode rectifier $i_{a}$ is of a quasi-square wave shape, and its amplitude is varying in opposite phase to the six-pulse output voltage of the rectifier. Figures 9 and 10 are the PLECS simulation result of the rectifier without and with third-harmonic current being applied

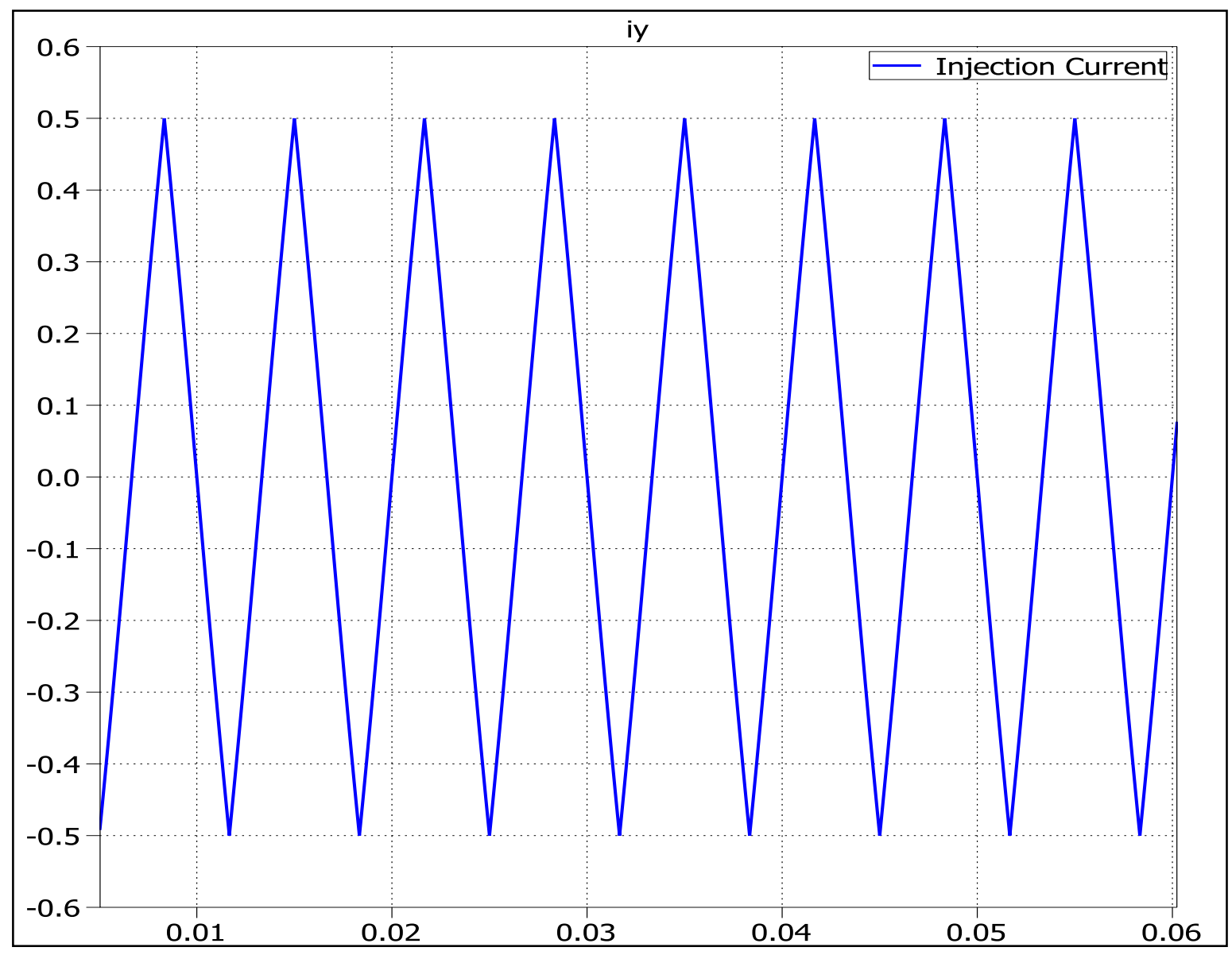

Figure 8. Injection current waveform (Ampere vs. Time) 


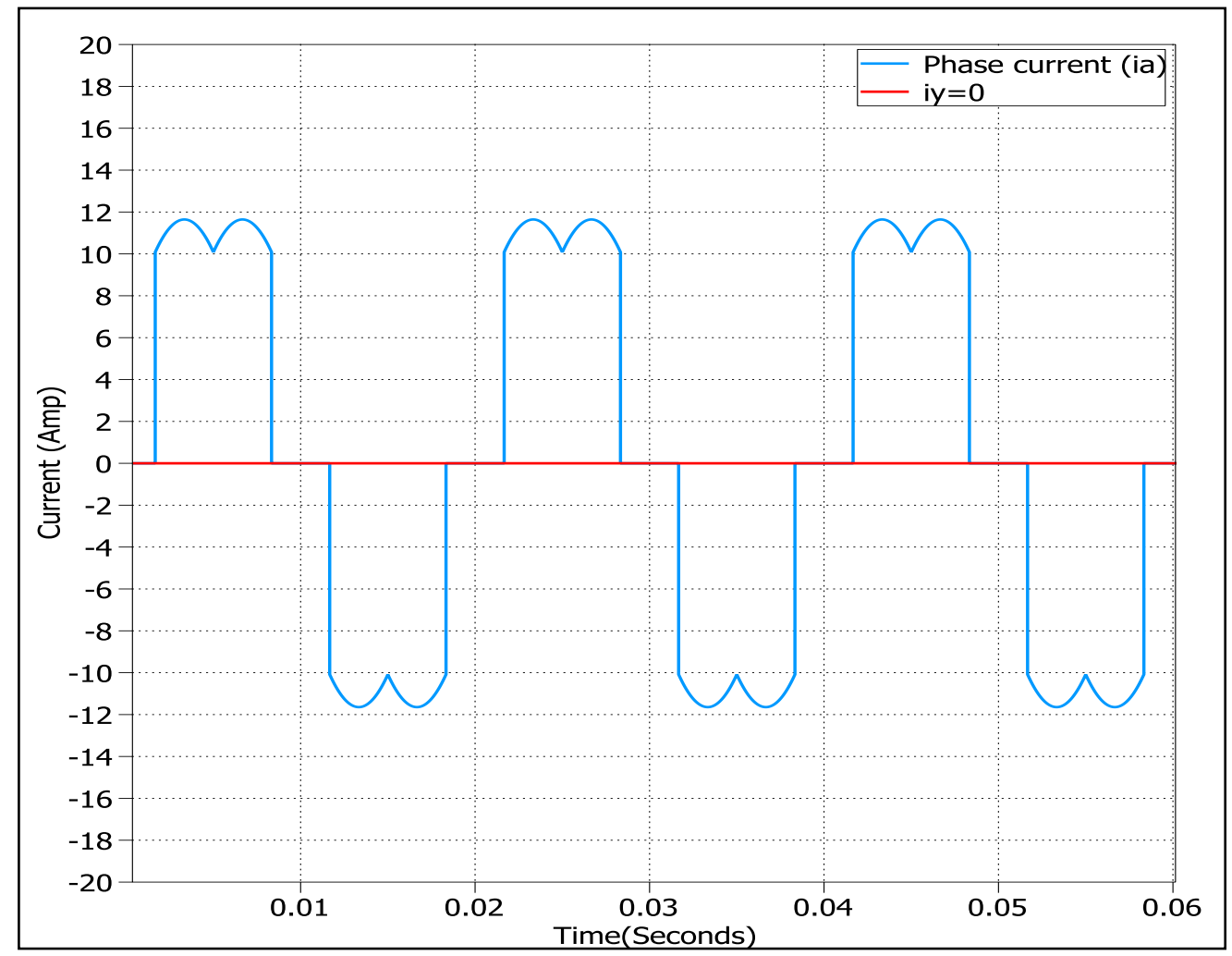

Figure 9. Simulation result of scaled supply current without current injection circuit

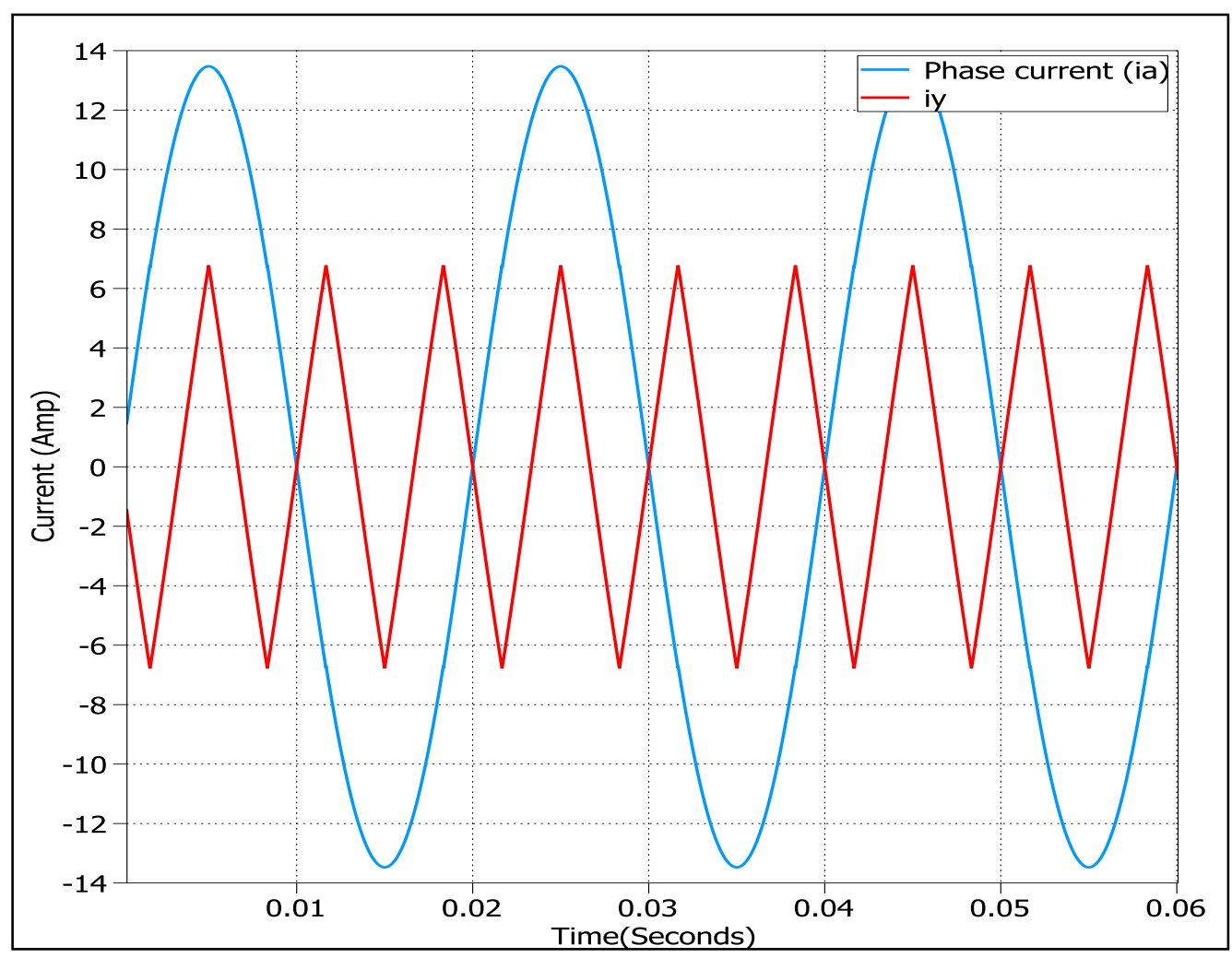

Figure 10. Simulation result of scaled supply current with current injection circuit

\section{Mathematical proof for sinusoidal shape input current}

For the Swiss rectifier shown in Figure 11, it has assumed that the switches $T_{+}$and $T_{-}$are switching with duty cycle $K_{1}$ and $K_{2}$ respectively. 


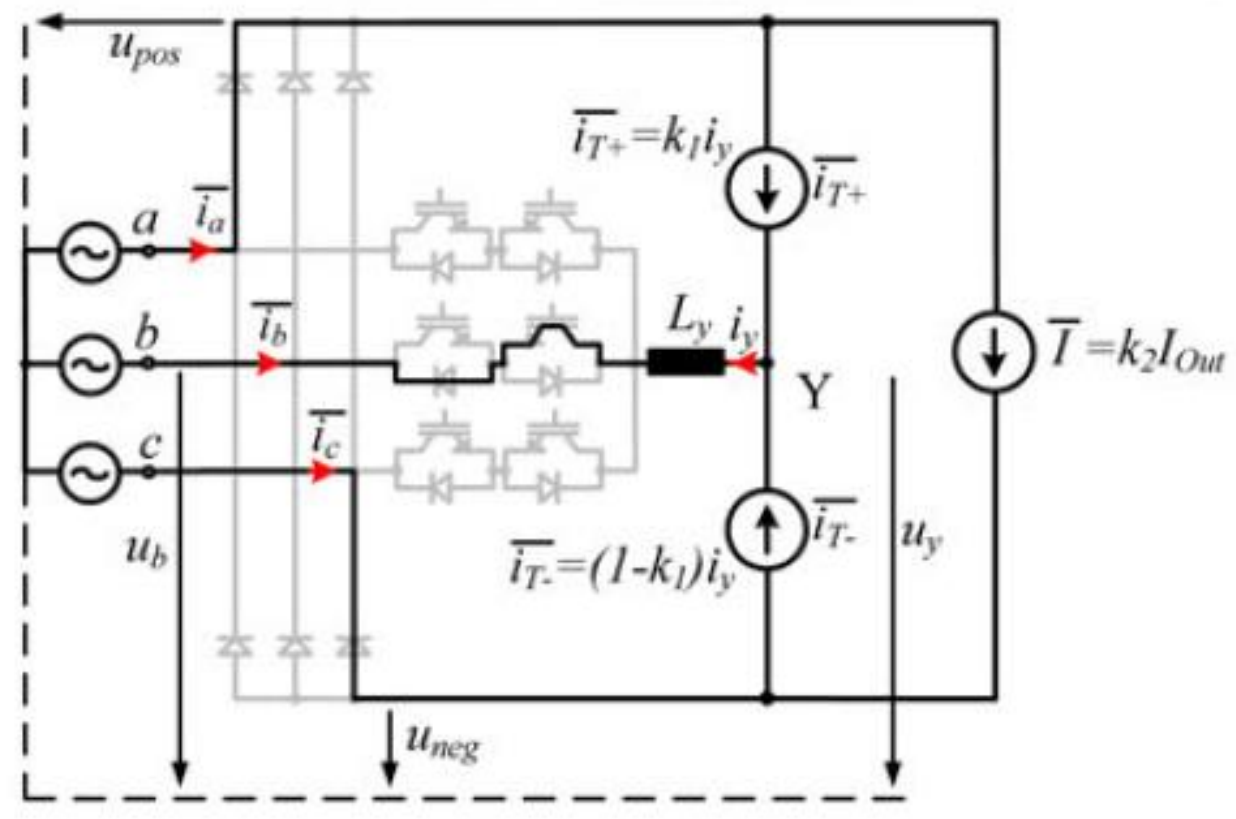

Figure 11. Equivalent circuit of Swiss rectifier [1]

The rectifier would be considered as three-phase symmetrical load with phase conductance G [1]. So, based on that, the value of the injected current in phase $b$ is given by the following equation:

$$
i_{y}=-i_{b}=-G V_{b}
$$

According to that, the voltage leg of the rectifier is given by:

$$
V_{y}=V_{b}
$$

The value of $K_{2}$ is equal to $\left(1-K_{1}\right)$, so this would result:

$$
V_{y}=K_{1} V_{a}+K_{2} V_{c}=K_{1} V_{a}+\left(1-K_{1}\right) V_{c}=K_{1} V_{a c}+V_{c}
$$

Form the rectifier circuit shown in Figure 11, the duty cycle $K_{1}$ is expressed as:

$$
\begin{aligned}
& V_{\text {pos }}=\max \left(V_{a}, V_{b}, V_{c}\right) \\
& V_{\text {neg }}=\min \left(V_{a}, V_{b}, V_{c}\right) \\
& K_{1}=\frac{-\left(V_{\text {pos }}+2 V_{\text {neg }}\right)}{V_{\text {pos }}-V_{\text {neg }}}=\frac{V_{b c}}{V_{a c}}
\end{aligned}
$$

Thus, the current flow through the switch $T_{+}$is described as:

$$
i_{T+}=K_{1} i_{y}=-K_{1} i_{b}=-K_{1} G V_{b}=-G V_{b} \frac{V_{b c}}{V_{a c}}
$$

Since the power is constant, therefore, the output current is given by: 


$$
\bar{I}=K_{2} I_{\text {out }}=\frac{P}{V_{a c}}=\frac{i_{a} V_{a c}+i_{b} V_{b c}}{V_{a c}}=G \frac{V_{a} V_{a c}+V_{b} V_{b c}}{V_{a c}}
$$

The current of phase a is proportional to the voltage of the main supply, where this voltage is sine wave in nature, therefore:

$$
i_{a}=\bar{I}+i_{T+}=G V_{a}
$$

By the same procedure, the current of phase $\mathrm{c}$ can be obtained and it is represented by the following equation:

$$
i_{c}=G V_{c}
$$

The formation of the current is as follows [12]:

$$
i_{a}+i_{b}+i_{c}=0
$$

Therefore, a current with sinusoidal shape for the mains interval $\left[0^{\circ}, 30^{\circ}\right]$ has been verified and the simulation waveform for three phase main current is shown in Figure 12.

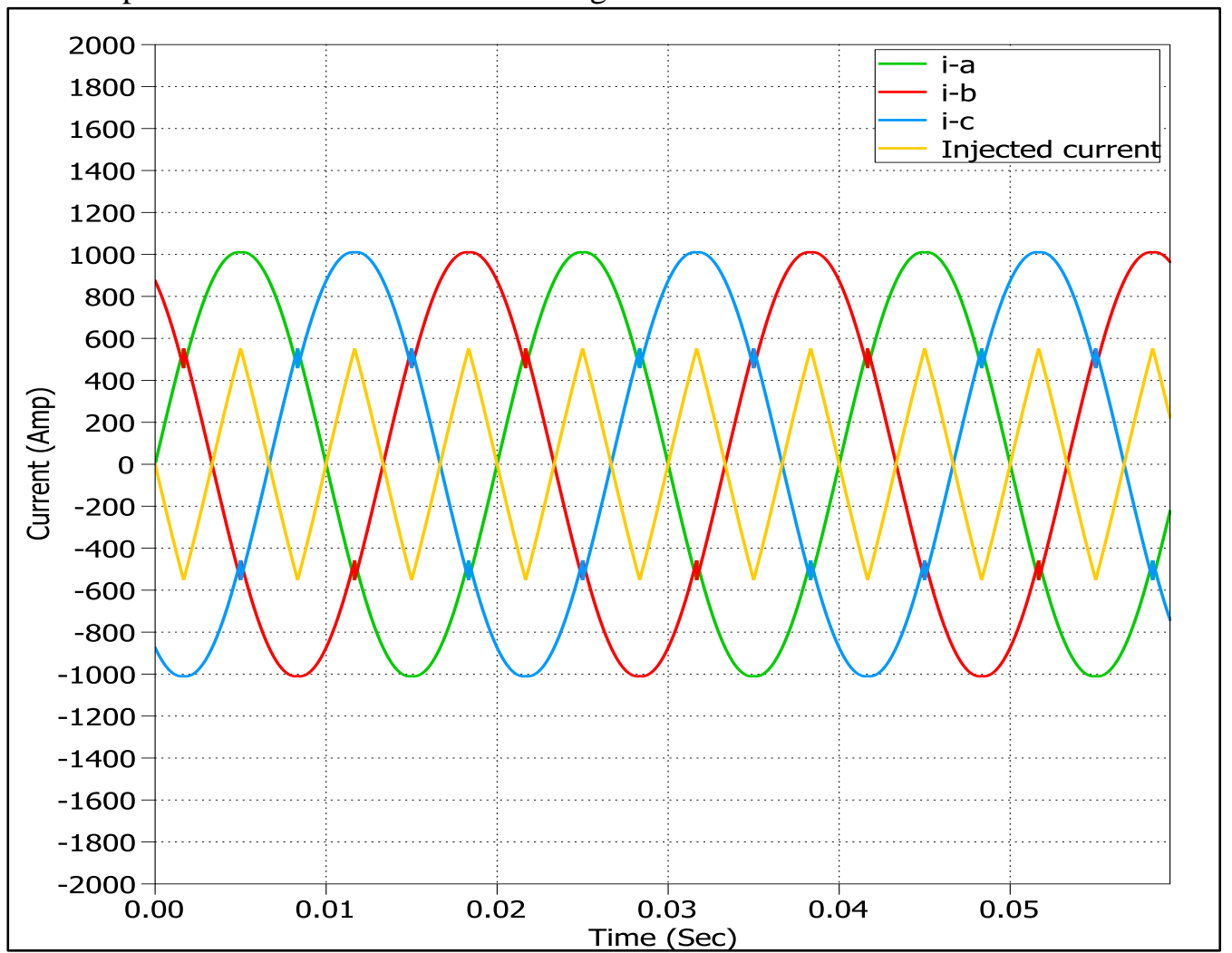

Figure 12. Mains current $\left(i_{a, b, c}\right)$ results of operation with current injection circuit by PLECS

The high rating and level of output voltage is an issue for the power electronic converters, where large stations and bulky transformer are required. In addition, higher number of voltage level would add extra cost and system complexity. The modular multilevel converter is solution for the mentioned issues, where high number of voltage level can be produced if an identical power electronic sub-modules are connected together in series. The modules can be easily added in order to obtain the redundancy and increase the reliability. The higher output voltage level, the more desirable output current and less need for the filtering. Thus, MMCs become the popular type for the Voltage Source Converter of HVDC. Therefore, a combination of Swiss rectifier and MMC would provide high voltage level and pure sinusoidal current in the input side; hence, this combination is suitable for HVDC application [11 - 15]. The simulation has conducted under the assumption of connecting the normal rectifier to a stiff AC grid and there is load on the DC side. The specifications of the rectifier are 
listed in Table 3. In the Swiss rectifier, each leg is considered as a high voltage controlled switch, where large number of IGBTs connected in series. Thus, each sub-module can be considered as a controlled DC voltage source, and each leg is as individual controllable voltage source. Based on that, the converter is seen as a controllable voltage source instead of actual sub-modules with IGBTs [19,20,27]. Figure 13 is the MMCSwiss rectifier, which is modelled in this paper.

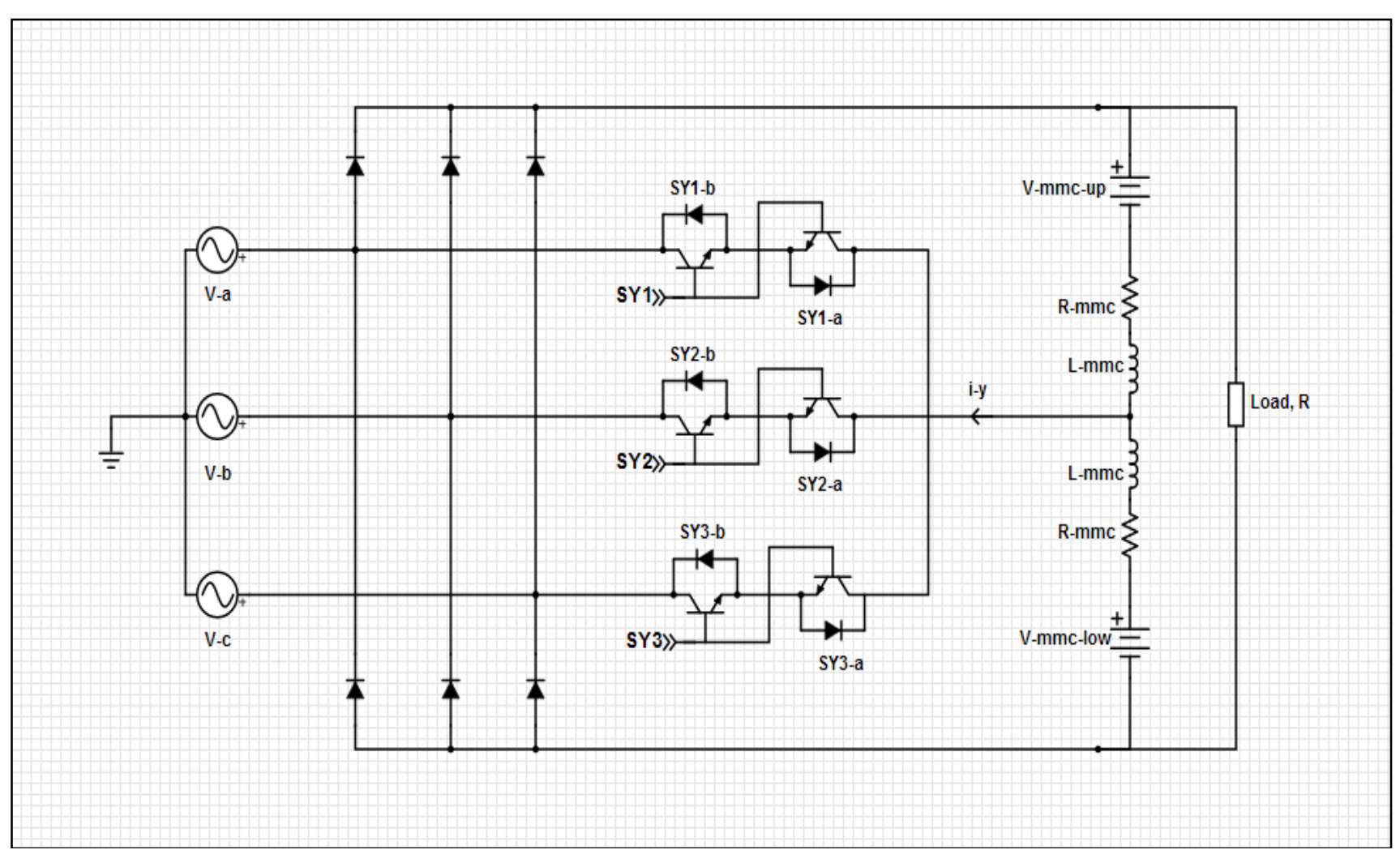

Figure.13. Circuit topology of MMC-Swiss rectifier by PLECS

Table 3: Rectifier specification

\begin{tabular}{|c|c|}
\hline Items & Values \\
\hline Input phase voltage, $\widehat{\mathbf{V}}_{\boldsymbol{a}, \boldsymbol{b}, \boldsymbol{c}}$ & $241.840 \mathrm{KV}$ \\
\hline Reference power, $\mathrm{p}$ & $400 \mathrm{MW}$ \\
\hline Main resistor, $\mathrm{R}$ & $400 \Omega$ \\
\hline MMC inductor, $\mathrm{L}$ & $0.0001 \mathrm{H}$ \\
\hline MMC resistor, $\boldsymbol{R}_{\boldsymbol{m} m \boldsymbol{c}}$ & $0.001 \Omega$ \\
\hline Mean sub-module voltage, $\overline{\boldsymbol{V}}_{\boldsymbol{s} \boldsymbol{m}}$ & $2 \mathrm{KV}$ \\
\hline Sub-module capacitor, $\boldsymbol{C}_{\boldsymbol{s m}}$ & $4 \mathrm{mF}$ \\
\hline
\end{tabular}


The waveform in Figure 14, is three-phase sinusoidal made up from the upper $\left(F_{+}\right)$,lower $\left(F_{-}\right)$and nonrectified $\left(F_{y}\right)$ components. Based on the previous analysis and calculations, $F_{+}, F_{-}$and $F_{y}$ can be easily derived.

$$
\left\{\begin{array}{l}
x_{a}=\hat{\mathrm{x}} \cos (w t) \\
x_{b}=\hat{\mathrm{x}} \cos \left(w t-\frac{2 \pi}{3}\right) \\
x_{c}=\hat{\mathrm{x}} \cos \left(w t-\frac{4 \pi}{3}\right)
\end{array}\right.
$$

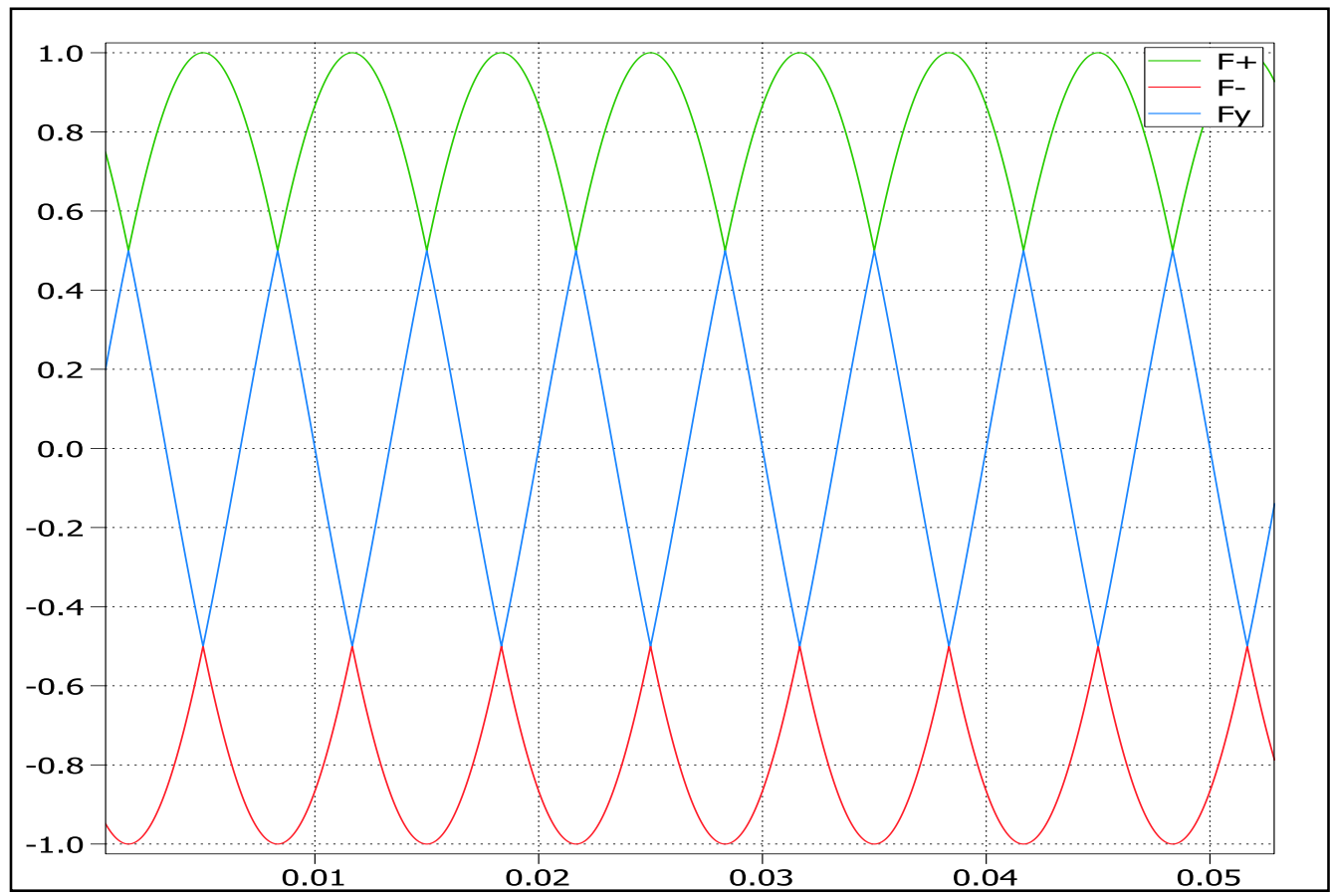

Figure.14: Upper, lower and non-rectified components, $F_{+}, F_{-}, F_{y}$

By using Fourier series, the positive rectified component can be expressed as:

$$
F_{+}=\frac{3 \sqrt{3}}{\pi} \hat{x}\left(\frac{1}{2}+\sum_{n=1}^{\infty} \frac{(-1)^{n+1}}{9 n^{2}-1} \cos (3 n w t)\right)
$$

The negative component is:

$$
F_{-}=\frac{3 \sqrt{3}}{\pi} \hat{\mathrm{x}}\left(-\frac{1}{2}+\sum_{n=1}^{\infty} \frac{1}{9 n^{2}-1} \cos (3 n w t)\right)
$$

From the point of view, the non-rectified component $F_{y}$, the blue waveform in the Figure 14, is a waveform of interest, which is obtained from the phase wave through the period when they are either at the maximum or minimum value $[6,25,26]$. However, the unrectified component can be easily calculated from the sum of the instantaneous values:

$$
x_{a}+x_{b}+x_{c}=0
$$

At every instant, one phase equals $F_{+}$, another equals to $F_{-}$, and the remaining equals to $F_{y}$. Therefore, the addition of output waveform and the unrectified components would equal to zero $[6,21,22]$. Thus, the expression of the unrectified component is:

$$
\begin{gathered}
F_{y}=-F_{+}-F_{-} \\
F_{y}=-\frac{3 \sqrt{3}}{\pi} \hat{x} \sum_{n=1}^{\infty} \frac{2}{(6 n-3)^{2}-1} \sin ((6 n-3) w t+\pi / 2)
\end{gathered}
$$




\section{Analytical approach}

Since the system is symmetrical, where the lower leg has the same result and calculation of the upper. Therefore, in this section, the calculations and analysis are based on the upper leg of the MMC, and the same can be obtained from the lower.

\section{A. The injected current}

The injected current can be easily obtained from the following:

$$
i_{y}=\hat{\mathrm{I}} F_{y}
$$

Where it is a multiple of the peak phase current and non-rectified component. Then, the peak to peak injected current can be calculated as:

$$
\hat{\mathrm{I}}_{y}= \pm \frac{3 \sqrt{3}}{\pi} \hat{\mathrm{I}} \sum_{n=1}^{\infty} \frac{2}{(6 n-3)^{2}-1}= \pm \frac{3 \sqrt{3}}{\pi} \cdot \hat{\mathrm{I}} \cdot \frac{\pi}{6 \sqrt{3}}= \pm \frac{1}{2} \hat{\mathrm{I}}
$$

Where Î is the converter peak to peak current. The mean power is given by:

$$
P=\frac{3}{2} \widehat{\mathrm{V}} \hat{\mathrm{I}}
$$

For the $400 \mathrm{MW}$ and $241.840 \mathrm{kV}$ system, the peak phase current is $1102 \mathrm{amp}$. The value of the peak diode current is 1100Amp, where the supply side inductances are small enough to be neglected.

$$
\hat{\mathrm{I}}_{\text {diode }}=\frac{\widehat{\mathrm{V}} \sqrt{3}}{R_{\text {total }}}
$$

\section{B. Voltage of upper leg}

It has mention before, that the modulation of the switches for harmonic current injection has six main sectors intervals $\left[0^{\circ}, 60^{\circ}\right]$ for each switch. The angle $\varphi$ is changing between $0^{\circ}$ and $360^{\circ}$. Therefore, the switches of MMC-Swiss rectifier are switched in an instant where they are in phase through the normal non-rectified periods. Figure 15 shows the relation between the positive rectified components $\left(F_{+}\right)$and non-rectified components $\left(F_{y}\right)$. It is clearly observed that $F_{y}$ and $F_{+}$have always $\pi / 6$ phase difference (half period of one sector).

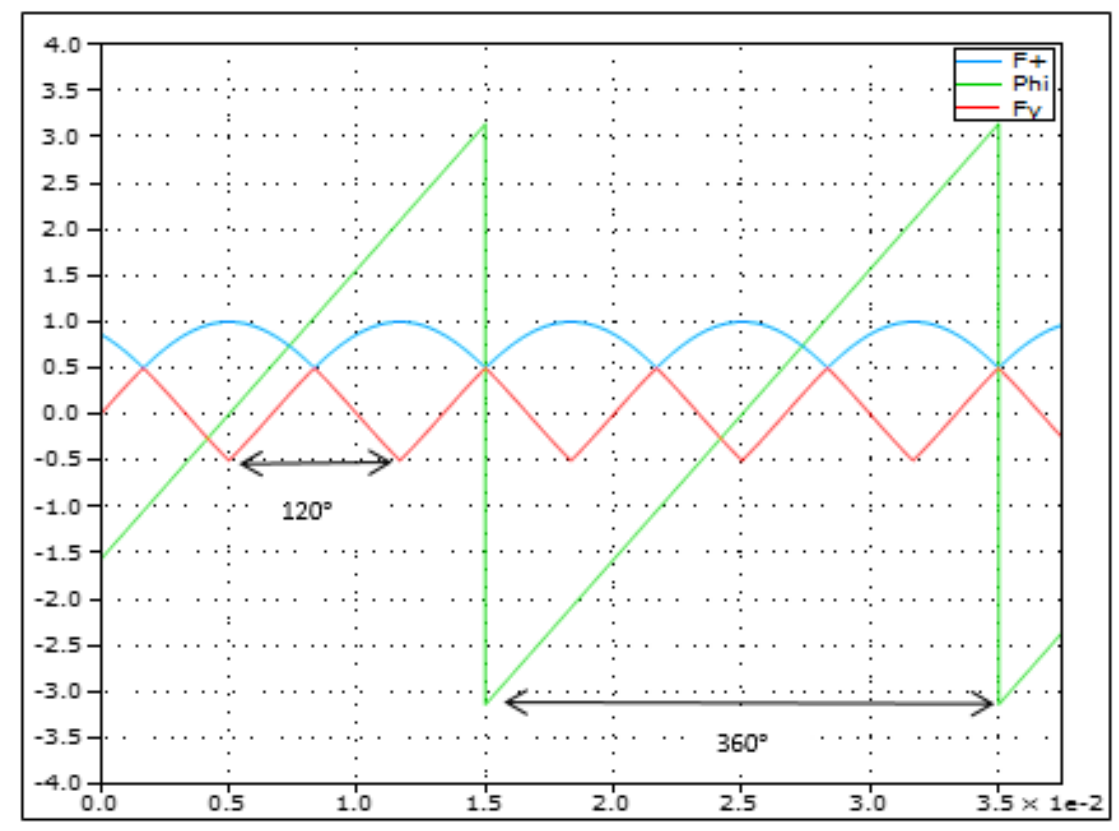

Figure.15. Relation between $\varphi, F_{+}$and $F_{y}$ 
For the purpose of simplification, the Clarke transformation has been used. The positive component $F_{+}$is a function of cosines and $F_{y}$ would be as a sine function. Due to the periodic waveform of $F_{+}$and $F_{y}$, the analytical calculations is performed through the interval between $-\pi / 3$ and $\pi / 3$. For a converter operation with current injection, the upper MMC voltage is:

$$
V_{m m c}^{u}=\widehat{\mathrm{V}}\left(F_{+}-F_{y}\right)
$$

where $\widehat{V}$ is input phase voltage. Therefore, MMC upper can be expressed as:

$$
V_{m m c}^{u}=\left\{\begin{array}{lc}
\widehat{V}\left(\cos \left(\varphi+\frac{\pi}{3}\right)-\sin \left(\varphi+\frac{\pi}{6}\right)\right) & -\pi / 3<\varphi<0 \\
\widehat{V}\left(\cos \left(-\varphi+\frac{\pi}{3}\right)-\sin \left(-\varphi+\frac{\pi}{6}\right)\right) & 0<\varphi<\pi / 3
\end{array}\right.
$$

When the cosine or sine function is equal to one, $\varphi=-\pi / 3$, the maximum and minimum value of the MMC upper voltage is obtained. Accordingly, the peak value of proposed rectifier voltage is $1.5 \widehat{V}$ or $362.76 \mathrm{kV}$.

\section{Current injection of upper leg}

In the MMC-Swiss rectifier, the current is divided into upper and lower leg, and the value of this current is half value of the injected current. Thus, the upper current of the MMC-Swiss rectifier is:

$$
i_{m m c}^{u}=\left\{\begin{array}{lc}
\frac{\hat{I}}{2} \sin (\varphi+\pi / 6) & -\pi / 3<\varphi<0 \\
\frac{\hat{I}}{2} \sin (-\varphi+\pi / 6) & 0<\varphi<\pi / 3
\end{array}\right.
$$

Therefore, the peak value of MMC-Swiss rectifier upper current is:

$$
\hat{\mathrm{I}}_{m m c}^{u}=\frac{\hat{\mathrm{I}}}{4}
$$

The peak value of the upper leg is 275.5Amp, which is obtained from the above formula, and the Root-MeanSquare (RMS) of the upper current of MMC-Swiss rectifier is $161.1 \mathrm{amp}$, which can be obtained from Equation (49).

$$
\mathrm{i}_{\mathrm{RMS}}^{\mathrm{u}}=\left[\frac{1}{\mathrm{~T}} \int_{0}^{\mathrm{T}} \mathrm{f}_{(\mathrm{t})}^{2} \mathrm{dt}\right]^{1 / 2}=\frac{3 \sqrt{3}}{4 \pi} \frac{\hat{\mathrm{I}}}{2 \sqrt{2}}
$$

The result for the lower leg of the converter is the same, but it should consider the negative sign for the phase current [21-24].

\section{Circulating current}

The average value of upper and lower leg currents would be named as the circulating current:

$$
i_{\text {circ }}=\frac{i_{m m c}^{u}+i_{m m c}^{l}}{2}
$$

The circulating current would have second harmonic component even if higher order harmonics are neglected $[19,20]$. The circulating current could damage the sub-modules and main converter, thus, this current must be reduced to a value that would guarantee safe operation. No mean power exchange is desired for the converter operation. Hence, in order to achieve that, the mean power must be forced to zero value. That can be performed by circulating the current that is injected into both legs, where if $i_{\text {circ }}$ is selecting such that:

$$
i_{c i r c}=\frac{2 \bar{p}_{M M C} u}{V_{D C}}
$$

The mean power Equation (43) and DC voltage values are obtained before, and from these values, the value of the circulating current of the MMC-Swiss rectifier is $86.45 \mathrm{amp}$. Moreover, the value of the upper and lower leg current would change when the $i_{\text {circ }}$ is injected. Thus, the new current of the MMC is: 


$$
\begin{gathered}
i_{m m c, \text { new }}^{u}=\left\{\begin{array}{lc}
\frac{\hat{\mathrm{I}}}{2} \sin (\varphi+\pi / 6)+i_{\text {circ }} & -\pi / 3<\varphi<0 \\
\frac{\hat{\mathrm{I}}}{2} \sin (-\varphi+\pi / 6)+i_{\text {circ }} & 0<\varphi<\pi / 3
\end{array}\right. \\
i_{\text {mmc,new }}^{l}=\left\{\begin{array}{lc}
-\frac{\hat{\mathrm{I}}}{2} \sin (\varphi+\pi / 6)+i_{\text {circ }} & -\pi / 3<\varphi<0 \\
-\frac{\hat{\mathrm{I}}}{2} \sin (-\varphi+\pi / 6)+i_{\text {circ }} & 0<\varphi<\pi / 3
\end{array}\right.
\end{gathered}
$$

The peak and RMS values of new current are 361.95 and $183.5 \mathrm{amp}$ respectively. The equivalent circuit of the MMC-Swiss rectifier is shown in Figure 16, and in this scheme, the MMC is represented by the voltage source.

The instantaneous power of the MMC is derived as:

$$
p_{M M C}^{u}=V_{m m c}^{u} \cdot i_{M M C}^{u}
$$

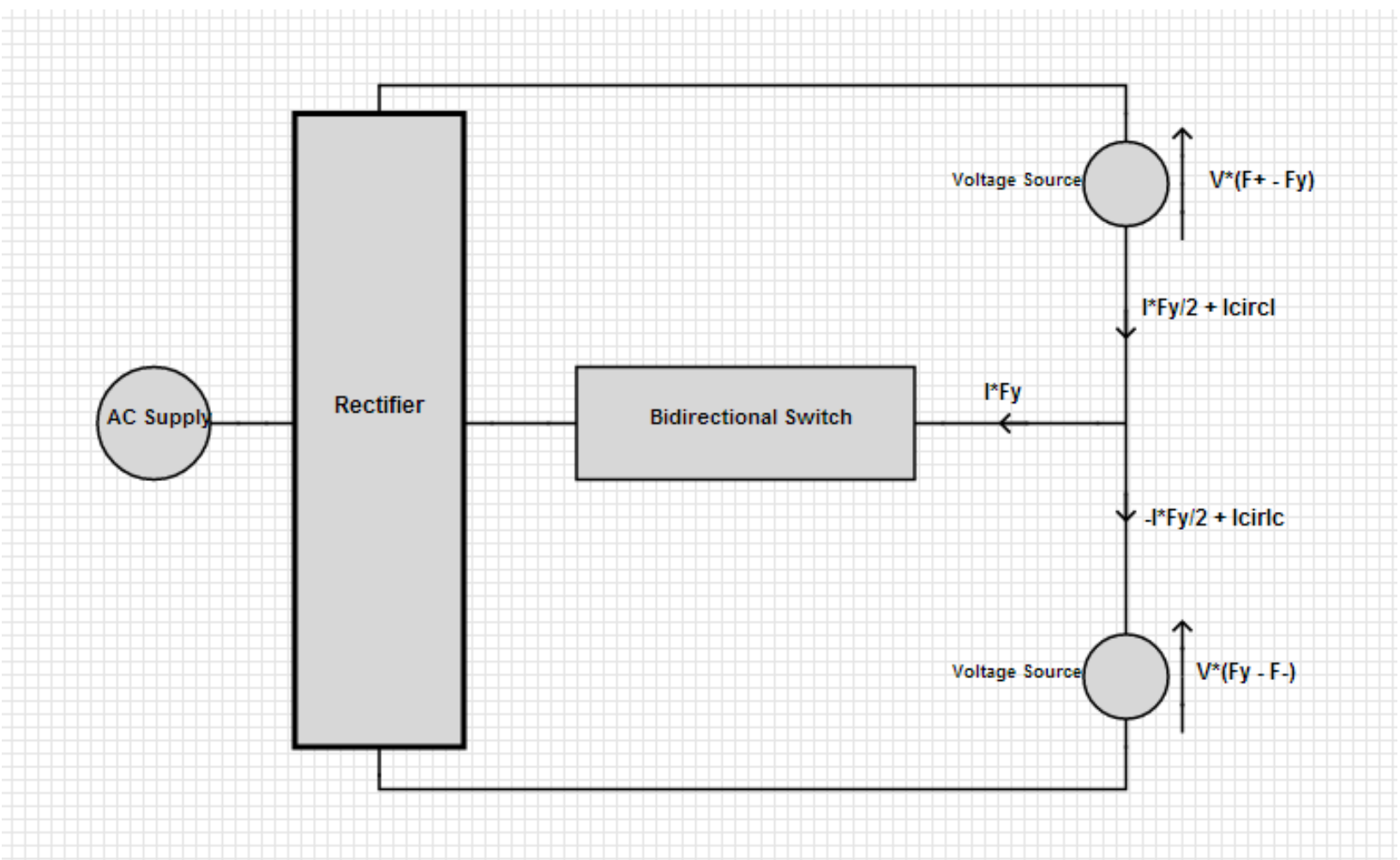

Figure 16. Equivalent schematic circuit of MMC-Swiss rectifier

By integrating the above equation, the mean power of $400 \mathrm{MW}, 241.840 \mathrm{kV}$ system can be obtaind:

$$
\begin{gathered}
\bar{p}_{M M C} u=\left(\frac{3}{2 \pi}\right)\left(\int_{-\frac{\pi}{3}}^{0} V_{m m c}^{u} \cdot i_{m m c}^{u}+\int_{0}^{\frac{\pi}{3}} V_{m m c}^{u} \cdot i_{m m c}^{u}\right) \\
\bar{p}_{M M C}{ }^{u}=\left(\frac{3}{2 \pi}\right)\left(\frac{\widehat{V} \hat{I}}{2}\right)\left(\frac{1}{8}(3 \sqrt{3}-2 \pi)+\frac{1}{8}(3 \sqrt{3}-2 \pi)\right)=-17.29 \mathrm{MW}
\end{gathered}
$$

Due to the small resistor value of each leg of the converter, the effect of $V_{\text {circ }}$ of the MMC is neglected. Hence, the new mean value of the power for the upper cell is:

$$
\bar{p}_{M M C}{ }^{u, n e w}=\left(\frac{3}{2 \pi}\right)\left(\int_{-\frac{\pi}{3}}^{0} V_{m m c}^{u} \cdot i_{m m c, n e w}^{u}+\int_{0}^{\frac{\pi}{3}} V_{m m c}^{u} \cdot i_{m m c, n e w}^{u}\right)
$$


The result of Equation (56) is approximately zero, therefore no mean power exchange has proven, moreover safe and sustained operation has achieved.

\section{Results and discussion}

The modelled MMC-Swiss rectifier by PLECS is shown in Figure 17 and the proposed system with control is in the Appendix.

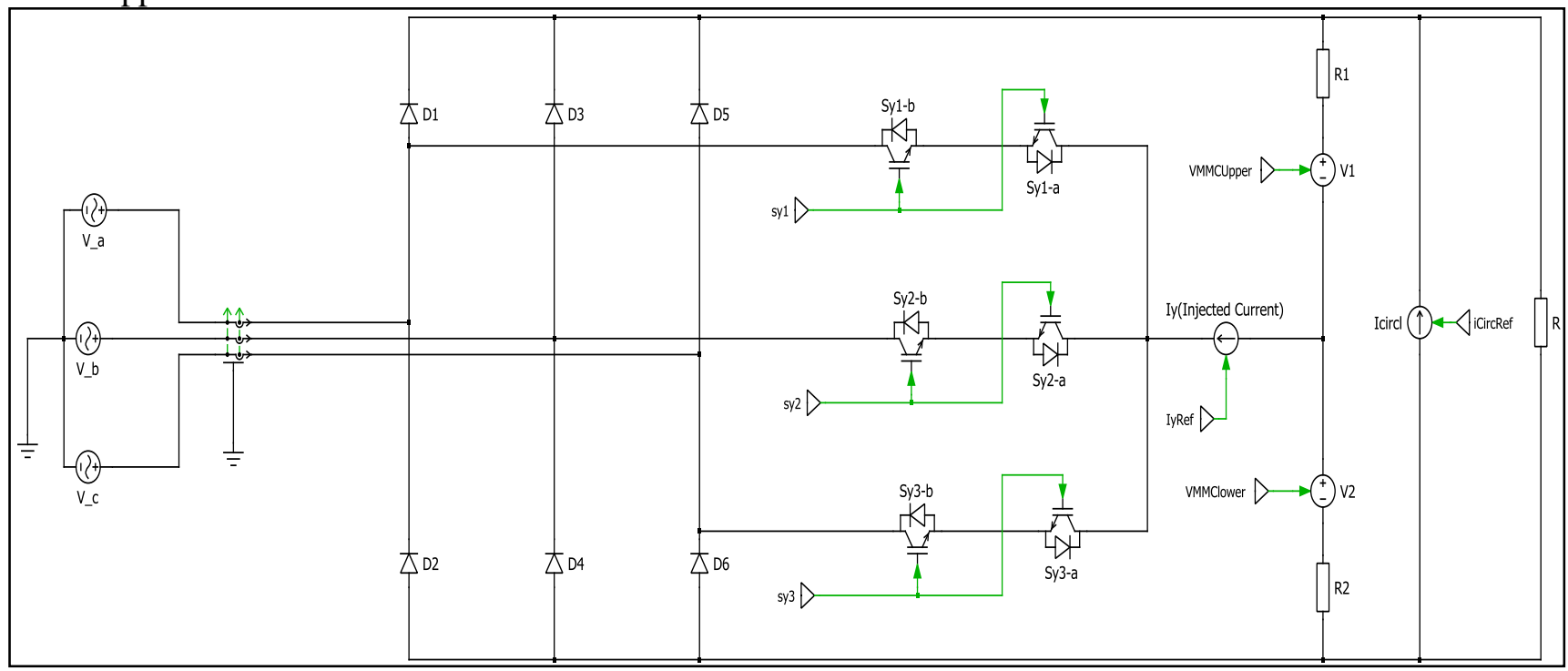

Figure 17. Proposed MMC-Swiss rectifier model in PLECS

The circulating current has injected in the upper and lower legs, and there would be circulating current and $F_{y}$ in each leg of the converter. The following response is the current and voltage of upper and lower leg.

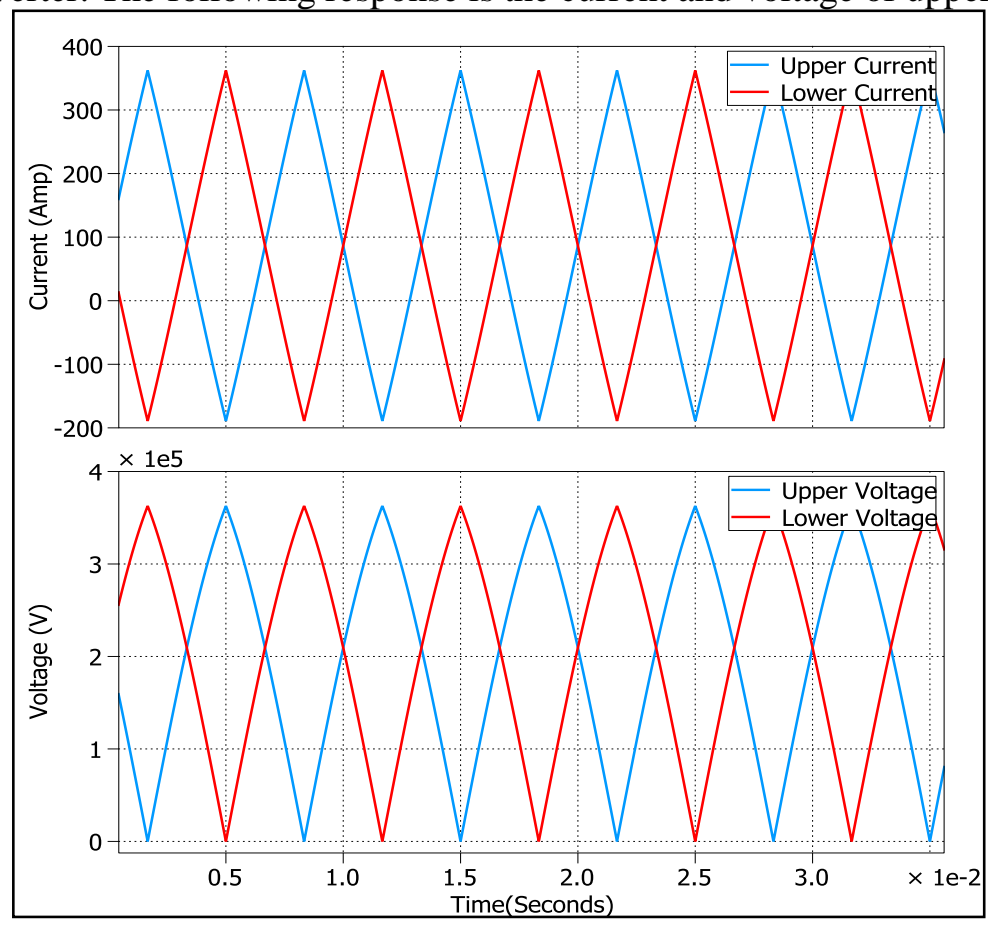

Figure 18: Responses of current and voltage in upper and lower arm 
From the current and voltage response, it has observed that they are symmetrical and the lower current/voltage is opposite to the upper current/voltage. The peak values of the current and voltage were calculated as $361.95 \mathrm{Amp}$ and $362.76 \mathrm{KV}$, respectively, and this shows the accuracy of the math calculations that has done before.

In Figure 19, it has observed that without circulating current being considered, the mean power of the rectifier is $-17.29 \mathrm{MW}$, which is based on Eq.55. Furthermore, by injecting appropriate circulating current, low average power exchange could be achieved, and this is shown in Figure 20.

The power response of Figure 19 and 20 shows the validity between the obtained mathematical results and simulated result. According to the parameters of the rectifier in Table 3, the results obtained from the mentioned equations and PLECS simulation are compared. It has noticed that there is accuracy of the calculations with the simulation results, as shown in Table 4.

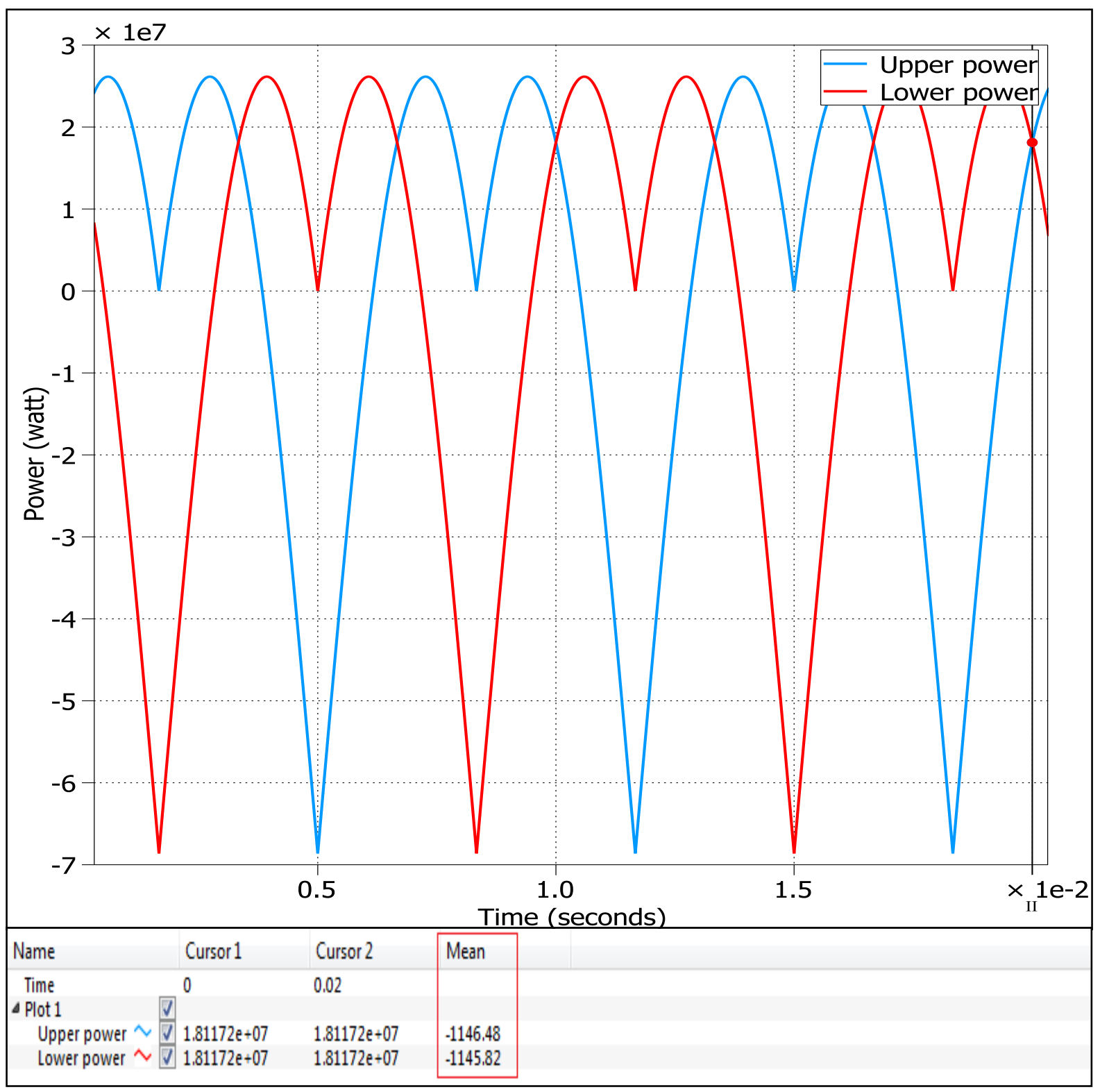

Figure 20. Power response with circulating current 


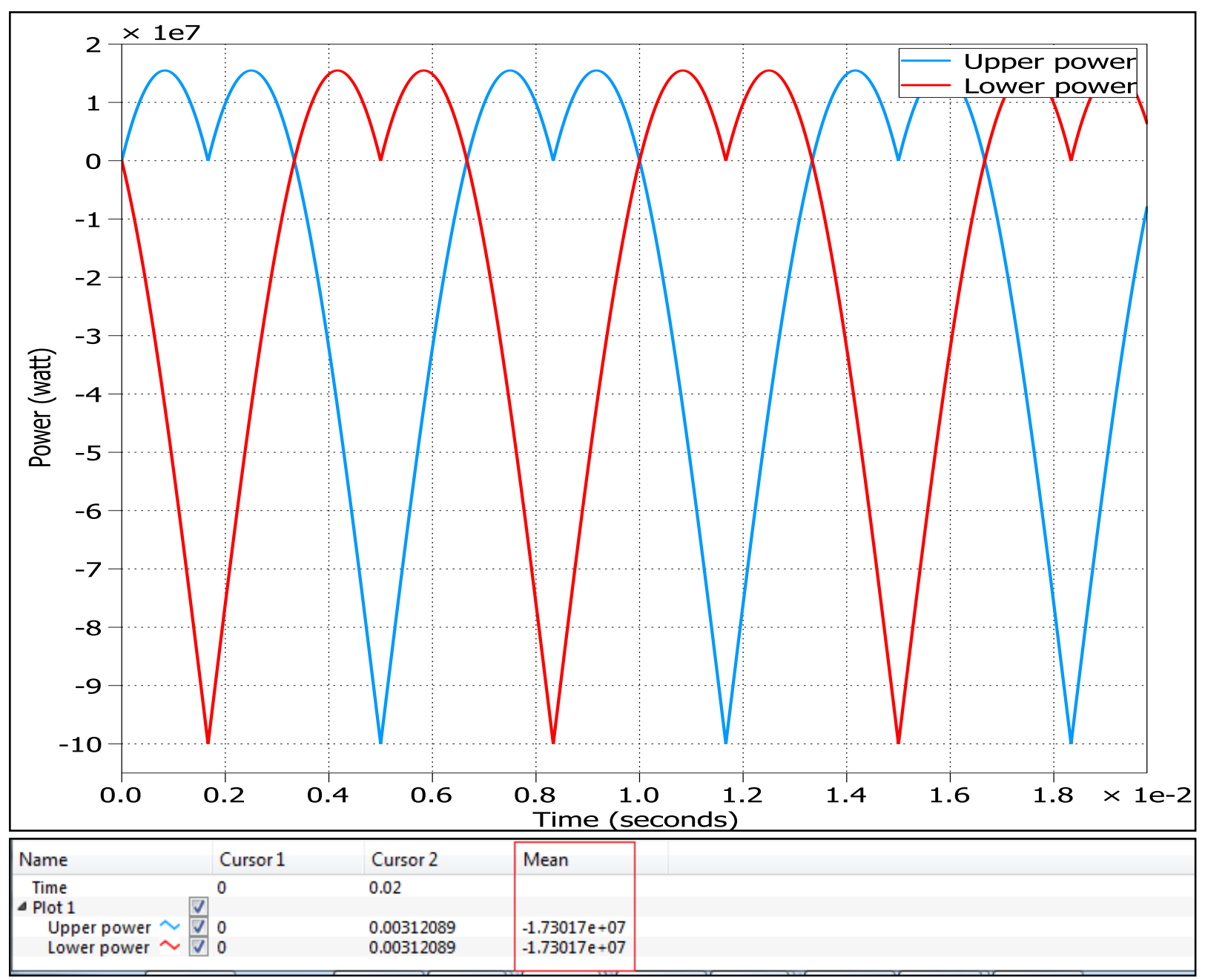

Figure 19. Power response without circulating current

\begin{tabular}{|c|c|c|c|}
\hline Parameters & $\begin{array}{c}\text { Analytical } \\
\text { Calculations }\end{array}$ & Simulation & Deviation (\%) \\
\hline Î (Amp) & 1102 & 1096.96 & -0.46 \\
\hline$\hat{\mathbf{I}}_{\text {diode }}(\mathrm{Amp})$ & 1100 & 1096.96 & 0.3 \\
\hline$\hat{\mathbf{I}}_{m m c}^{u}(\mathbf{A m p})$ & 275.5 & 275.664 & 0.06 \\
\hline$i_{R M S}^{u}(\mathrm{Amp})$ & 161.1 & 161.749 & 0.4 \\
\hline$\hat{\mathbf{I}}_{M M C, \text { new }}^{u}(\mathrm{Amp})$ & 361.95 & 362.1 & 0.04 \\
\hline$i_{R M S, n e w}^{u}(\mathrm{Amp})$ & 183.5 & 183.477 & -0.012 \\
\hline$W_{\text {Total }}^{\text {sm }}($ Joules $)$ & 8.06 & 8.069 & 0.1 \\
\hline$\Delta E^{\max }($ Joules) & 1320 & 1212 & -8 \\
\hline $\bar{p}_{M M C}{ }^{u}($ Watt $)$ & -17290336 & -17301700 & 0.065 \\
\hline$\widehat{\mathbf{V}}_{m m c}^{u}(\mathbf{V})$ & 362760 & 362760 & 0 \\
\hline$V_{\max }^{s m}(\mathbf{k V})$ & 2.074 & 2.048 & -1.2 \\
\hline$V_{\max }^{s m}(\mathrm{kV})$ & 1.926 & 1.950 & 1.5 \\
\hline
\end{tabular}


From the obtained result, the converter performance has improved, and the current drawn by the converter is sinusoidal. Where the total harmonic distortion has reduced tremendously. The simulation and design process have been performed for a converter with nominal power of 400MW and 400KV DC voltage in order to certify the approach used in the calculation steps. Where, there is minor difference between the simulation and calculation results.

The results that have obtained from the mathematical analysis and PLECS simulation are matched. The MMC-Swiss rectifier has designed, the value of the leg inductance and resistance used in the simulation are small to the extent that can be neglected. The MMC-Swiss rectifier has been implemented on PLECS and various responses have been obtained. The controllable voltage source has considered as a MMC with 200 sub-module connected in series.

\section{Conclusions}

The VSCs considered as more suitable selection for HVDC applications compared to other types of converters. However, the modular multilevel converters (MMC) has proven its high efficiency and robustness as a converter. In addition, it contributes to reduce the HVDC stations because of its contribution of minimising the size of required filters as well as eliminating low order harmonics. The MMC-Swiss rectifier has employed in this paper to inject third-harmonic current to improve the quality of drawn AC current by the rectifier for HVDC applications. The simulation model was conducted by inserting three switches in the main current path, which acts as a circuit for third-harmonic current injection. The combination of MMC and Swiss rectifier ensure more flexible in terms of voltage and current sustainability, also the THD of the AC input current has improved without affecting the other equipment. The analytical calculations of the converter parameters have shown a good match with the obtained result from simulation with very low error.

\section{References}

[1] B. Soeiro, F.Vancu, J.W. Kolar, "Hybrid Active Third-Harmonic Current Injection Mains Interface Concept for DC Distribution Systems", Power Electronics, IEEE Transactions on Volume:28 , Issue: 1, pp 7 - 13, Jan. 2013.

[2] B. Soeiro, J.W. Kolar, T. Friedli, "Swiss rectifier - A novel three-phase buck-type PFC topology for Electric Vehicle battery charging", Applied Power Electronics Conference and Exposition (APEC), 2012 Twenty-Seventh Annual IEEE, pp. 2617 - 2624, 5-9 Feb. 2012.

[3] AD. Rajapakse, AM. Gole, PL. Wilson, "Electromagnetic transients simulation models for accurate representation of switching losses and thermal performance in power electronic systems", Power Delivery, IEEE Transactions on (Volume:20 , Issue: 1), PP. 319 - 327, Jan 2005.

[4] J. W. Kolar and T. Friedli, "The Essense of Three-Phase PFC Rectifier Systems", in Proc. 33rd IEEE Int. Telecom. Energ. Conf (INTELEC 2011), Oct. 9-13, pp. 1-27, 2011.

[5] J. W. Kolar, M. Hartmann and T. Friedli, "Three-Phase Unity Power Factor Mains Interfaces of High Power EV Battery Charging Systems", in Power Electronics for Charging Electric Vehicles ECPE Workshop, Mar. 2011.

[6] P. Pejovic (2007), “Three-Phase Diode Bridge Rectifier with Low Harmonics”, PP. 7-21, Springer US press.

[7] L. Xiaoqing, G. Chen, "Harmonic suppression technology of three-phase diode rectifier based on third harmonic current injection", Power Electronics and Applications, European Conference on Aalborg, PP. 1-9, 2-5 Sept. 2007.

[8] S.M.Muyeen, R.Takahashi, T.Murata, and J.Tamura“Control strategy for HVDC interconnected DCbased offshore wind farm, " Electrical Machines and Systems, 2009. ICEMS 2009. International Conference.

[9] R. Feldman, M. Tomasini, J. Clare, P. Wheeler, D. Trainer, and R. Whitehouse, "A Low Loss Modular Multilevel Voltage Source Converter for HVDC Power Transmission and Reactive Power Compensation," in IET-ACDC 2010, London, United Kingdom, Oct. 20-21 , 2010. 
[10] J. Pan, R. Nuqui, K. Srivastava, T. Jonsson, P. Holmberg, and Y.-J. Hafner, "AC Grid with Embedded VSC-HVDC for Secure and Efficient Power Delivery," in Energy 2030 Conference, 2008. ENERGY 2008. IEEE, 17-18 2008, pp. $1-6$.

[11] N. Flourentzou, V. Agelidis, and G. Demetriades, "VSC-Based HVDC Power Transmission Systems: An Overview," Power Electronics, IEEE Transactions on, vol. 24, no. 3, pp. 592 -602, March 2009.

[12] Schettler, H. Huang, and N. Christl, "HVDC transmission systems using voltage sourced converters design and applications," in Power Engineering Society Summer Meeting, 2000. IEEE, vol. 2, 2000, pp. $715-720$ vol. 2.

[13] E.Spahic, G.Balzer "Offshore wind farms - VSC-based HVDC connection," Power Tech, 2005 IEEE St. Petersburg, Russia.

[14] F.Obeidat, X.Lie, L.Yongdong, "Simulation of grid connected HVDC offshore wind farm topologies," Power Electronics and Drive Systems (PEDS), 2013 IEEE 10th International Conference.

[15] Michael Bahrman, et al. "Asynchronous back-to-back HVDC link with voltage source converters", at Minnesota Power Systems Conference, November 1999, USA

[16] Vijay K. Sood. "HVDC and FACTS controllers: application of static converters in power systems" Boston ; London : Kluwer Academic Publishers, c2004.

[17] F.T. Ghetti, A. Ferreira, H. Braga, P. Barbosa "“A study of shunt active power filter based on modular multilevel converter (MMC)", Industry Applications (INDUSCON), 2012 10th IEEE/IAS International Conference, PP. 1 - 6, 5-7 Nov. 2012, Fortaleza.

[18] Ashish B Chaudhari, S. Jebarani Evangeline, "Space Vector Pulse Width Modulation Technique to Reduce the Effects of Voltage Unbalances", International Journal of Engineering and Advanced Technology (IJEAT) ISSN: 2249 - 8958, Volume-3, Issue-4, April 2014.

[19] Amankwah, J. Clare, P. Wheeler, and A. Watson, "Cell capacitor voltage control in a parallel hybrid modular multilevel voltage source converter for HVDC applications ," in IET-PEMD 2012, Bristol, United Kingdom, Mar. 27-29, 2012.

[20] Maryam Saeedifard, Reza Iravani, "Dynamic Performance of a Modular Multilevel Back-to-Back HVDC System", IEEE Transactions on Power Delivery, vol. 25, no. 4, October 2010.

[21] P. Bozovic, p. Pejovic, "Current-injection based low harmonic three-phase diode bridge rectifier operating in discontinuous conduction mode"Electric Power Applications, IEE Proceedings (Volume:152, Issue: 2 ), 4 March 2005

[22] P. Pejovic, "Two three-phase high power factor rectifiers that apply the third harmonic current injection and passive resistance emulation", Power Electronics, IEEE Transactions on Volume:15, Issue: 6, PP. 1228 - 1240, Aug. 2002.

[23] B. Jacobson, P. Karlsson, G. Asplund, L. Harnefors and T. Jonsson, "VSC-HVDC Transmission with Cascaded Two-Level Converters", CIGRE 2010.

[24] M.Sleiman, et al, "A survey on modeling, control, and dc-fault protection of modular multilevel converters for HVDC systems", Industrial Electronics (ISIE), 2014 IEEE 23rd International Symposium, PP. 2149 - 2154, 1-4 June 2014, Istanbul, Turkey.

[25] Barazanchi, I. Al, Abdulshaheed, H.R., Shawkat, S.A., and Binti, S.R., 2019. Identification key scheme to enhance network performance in wireless body area network. Periodicals of Engineering and Natural Sciences, 7 (2), pp.895-906.

[26] Rashid, S., Ahmed, A., Barazanchi, I. Al, and Jaaz, Z.A., 2019. Clustering algorithms subjected to Kmean and gaussian mixture model on multidimensional data set. Periodicals of Engineering and Natural Sciences, 7 (2), pp.448-457.

[27] B. Durakovic, "Design of Experiments Application, Concepts, Examples: State of the Art," Periodicals of Engineering and Natural Scinces, vol. 5, no. 3, p. 421-439, 2017. 


\section{Appenidx A:}

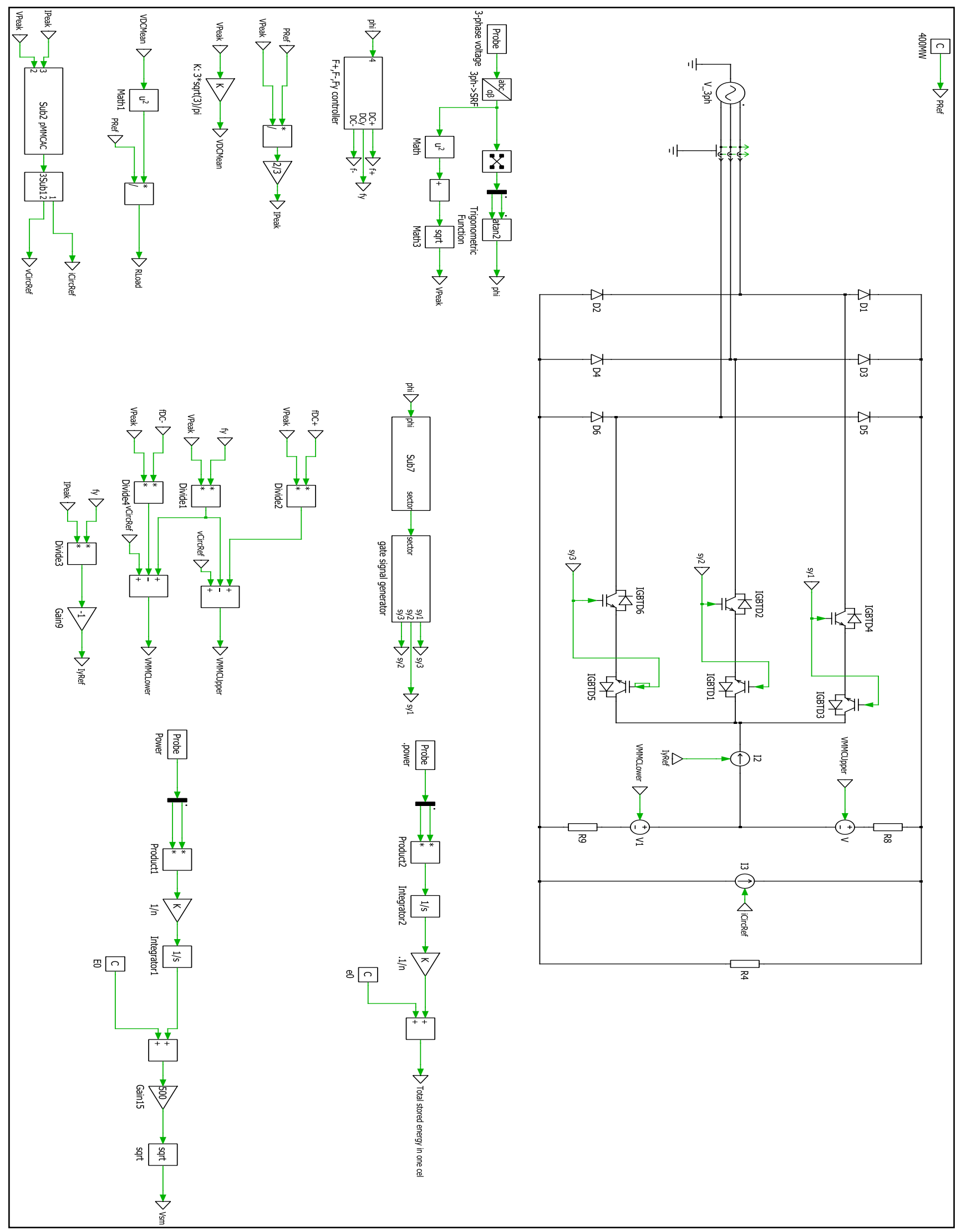

Figure A: Proposed MMC-Swiss rectifier model in PLECS 